$1 / 1 / 12-94850$

SANDIA REPORT

SAND94-0587 • UC-701

Unlimited Release

? Printed October 1994

Kinetics of the Wetting of Tin on Air-Passivated Copper in the Absence of a Fluxing Agent

D. E. Peebles, H. C. Peebles, J. A. Ohlhausen, F. G. Yost

Propared by

Sandla National Laboratorles

Albuquerque, Now Mexlco 87185 and Livermore, Callfornla $\mathbf{9 4 5 5 0}$

for the United States Department of Energy

under Contract DE-ACO4-94AL85000

Approved for public release; distribution is unlimited. 
Issued by Sandia National Laboratories, operated for the United States Department of Energy by Sandia Corporation.

NOTICE: This report was prepared as an account of work sponsored by an agency of the United States Government. Neither the United States Government nor any agency thereof, nor any of their employees, nor any of their contractors, subcontractors, or their employees, makes any warranty, express or implied, or assumes any legal liability or responsibility for the accuracy, completeness, or usefulness of any information, apparatus, product, or process disclosed, or represents that its use would not infringe privately owned rights. Reference herein to any specific commercial product, process, or service by trade name, trademark, manufacturer, or otherwise, does not necessarily constitute or imply its endorsement, recommendation, or favoring by the United States Government, any agency thereof or any of their contractors or subcontractors. The views and opinions expressed herein do not necessarily state or reflect those of the United States Government, any agency thereof or any of their contractors.

Printed in the United States of America. This report has been reproduced directly from the best available copy.

Available to DOE and DOE contractors from

Office of Scientific and Technical Information

PO Box 62

Oak Ridge, TN 37831

Prices available from (615) 576-8401, FTS 626-8401

Available to the public from

National Technical Information Service

US Department of Commerce

5285 Port Royal RD

Springfield, VA 22161

NTIS price codes

Printed copy: A04

Microfiche copy: A06 


\section{DISCLAIMER}

Portions of this document may be illegible in electronic image products. Images are produced from the best available original document. 
SAND94-0587

Distribution

Unlimited Release

Printed October 1994

Category UC-701

\title{
Kinetics of the Wetting of Tin on Air-Passivated Copper in the Absence of a Fluxing Agent ${ }^{*}$
}

\author{
D E. Peebles, H. C. Peebles, J. A. Ohlhausen and F. G. Yost \\ Center for Solder Science and Technology \\ Sandia National Laboratories \\ Albuquerque, New Mexico 87185-0367
}

\begin{abstract}
A specially designed ultrahigh vacuum in situ surface analysis and wetting system has been constructed to study the spreading of liquid metal solders on carefully prepared and well-characterized solid substrates. Initial studies have been completed for the spreading of pure tin solder on copper substrates in the absence of any fluxing agent. Three types of copper substrate surfaces were investigated in these experiments: the sputter-cleaned, the air-exposed and the as-received surface. Surface chemical analysis by $\mathrm{x}$-ray photoelectron spectroscopy showed the air-exposed surface to consisted of about $3 \mathrm{~nm}$ of $\mathrm{Cu}_{2} \mathrm{O}$, while the as-received surface consisted of about $8 \mathrm{~nm}$ of $\mathrm{Cu}_{2} \mathrm{O}$. The sputter-cleaned surface contained less than one monolayer $(0.3 \mathrm{~nm})$ of $\mathrm{Cu}_{2} \mathrm{O}$. Sample surfaces were prepared and spreading experiments performed without intermediate exposure of the surfaces to contaminating atmospheres. Solder spreading was performed under 50 torr of highly purified helium gas to allow for adequate thermal coupling between the solder and the substrate. Spreading experiments utilizing a linear temperature ramp show that pure tin solder spreads readily on oxidized copper surfaces at elevated temperatures. The initiation temperature for rapid tin spreading on the as-received copper surface was $325^{\circ} \mathrm{C}$, similar to the temperature where isothermal spreading changes activation energy or rate. Decreasing the thickness of the oxide on the surface lowered the observed temperature for the initiation of spreading and increased the rate of spreading. On the sputter-cleaned copper surface, rapid solder spreading was observed immediately upon melting of the solder. Isothermal spreading experiments were performed on the as-received copper surface in the temperature range between 262 and $331^{\circ} \mathrm{C}$. Measurable solder spreading was observed on this surface even at temperatures only $30^{\circ} \mathrm{C}$ above the melting temperature of the pure tin solder $\left(232^{\circ} \mathrm{C}\right)$. The results of the isothermal experiments show that solder spreading on the as-received copper surface is an activated process with an activation energy of $39.4 \pm 3.1 \mathrm{kcal} / \mathrm{mole}$ in the range of 262 and $327^{\circ} \mathrm{C}$. Above $327^{\circ} \mathrm{C}$, a discontinuity in the Arrhenius plot is observed which is associated with a decrease in the oxide thickness present on the surface as a result of surface desorption or diffusion into the bulk copper. Metallurgical cross section analysis after spreading on the as-received surface shows the expected formation of $\mathrm{Cu}-\mathrm{Sn}$ intermetallic zones and microstructure with no gaps at the $\mathrm{Cu}-\mathrm{Sn}$ interface due to remaining patches of copper oxide.
\end{abstract}

* This work was performed at Sandia National Laboratories in collaboration with the National Center for Manufacturing Sciences under CRADA number CR91/1030, supported by the U. S. Department of Energy (DOE) under contract number DE-AC04-94AL85000. 


\section{Acknowledgments}

The authors wish to thank Michael Hurst for his extensive help in procuring and assembling experimental hardware for this study as well as for the preparation of the tin solder balls. The authors also wish to thank Amadeo Carter and Alice Kilgo for the preparation of metallographic samples and the micrographs used in Figure 14. The authors thank Darrel Frear for allowing us to use the solder spreading rate data for $\mathrm{Sn} / \mathrm{Pb}$ eutectic solder with Kester 197 RMA flux to compare to theory in Figure 1. Finally, the authors acknowledge discussions with Michael Hosking, Robert Rye and Julian Mann which have proven helpful in exploring the ideas and directions of possible research in the area of spreading. 


\section{Contents}

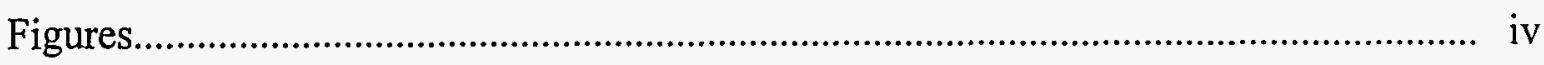

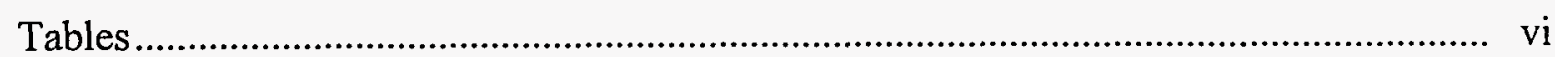

Nomenclature ................................................................................................ vii

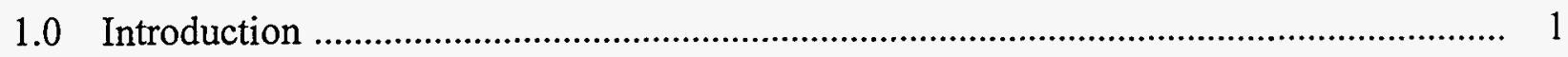

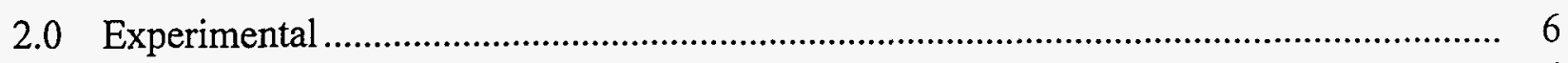

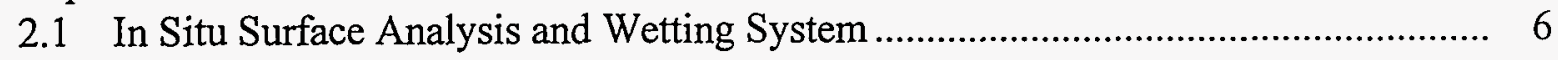

2.2 Materials Preparation ...................................................................................... 8

2.2.1 Pure Tin Solder Balls .................................................................................. 8

2.2.2 Copper Substrates ............................................................................... 9

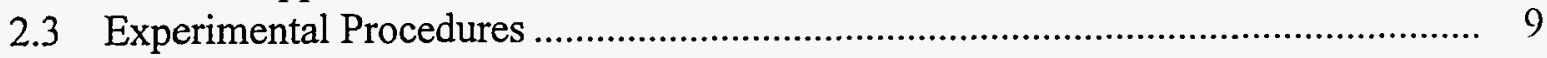

2.3.1 Helium Pressure Dependence Measurements .............................................. 9

2.3.2 Temperature Ramp Spreading Experiments ................................................ 10

2.3.3 Isothermal Spreading Experiments ............................................................. 11

2.3.4 Surface Composition and Chemistry Measurements..................................... 11

2.4 Video Monitoring and Image Analysis ............................................................... 12

3.0 Results and Discussion ....................................................................................... 15

3.1 Ambient Pressure Dependence Experiments ........................................................... 15

3.2 Temperature Ramp Spreading Experiments ............................................................ 17

3.3 Isothermal Spreading Kinetics on the As-Received Copper Surface......................... 21

3.4 Metallurgical Analysis ....................................................................................... 26

3.5 Surface Chemistry ............................................................................................ 27

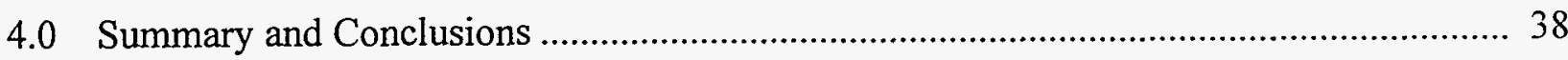

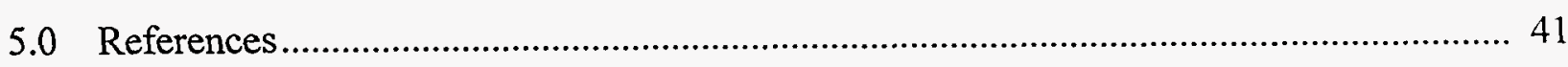

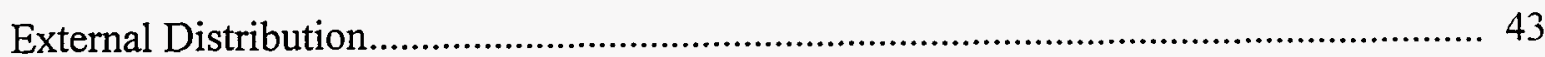

Internal Distribution......................................................................................... 44 


\section{Figures}

1. Comparison of experimental spreading kinetics of tin/lead solder to that predicted by de Gennes' theory using appropriate values of the viscosity and surface tension for the solder

2. Illustration of some of the complex chemical interactions which occur for tin/lead solder spreading on an oxidized copper substrate

3. Schematic illustration of the In Situ Surface Analysis and Wetting system especially designed for the determination of the effects of surface chemical state on the kinetics of the wetting and spreading of liquid metals on solid surfaces

4. Schematic illustration of the setup used for the collection of video information during the real-time monitoring of solder spreading

5. Examples of side view and top view video frames shortly after dropping a tin solder ball onto a copper substrate at $280.0^{\circ} \mathrm{C}$

6. Apparent melting temperature of pure tin solder balls on as-received copper substrates as a function of ambient helium pressure in the reaction chamber

7. Temperature versus time function used for temperature estimates in temperature ramp spreading experiments where a thermocouple could not be used.

8. Spreading of pure tin solder on the as-received copper surface as a function of sample temperature during a temperature ramp experiment in 50 torr purified helium

9. Results of temperature ramp experiments for the spreading of pure tin solder on three different copper substrates of varying surface oxide thickness

10. Isothermal spreading of pure tin solder on the as-received copper surface as a function of time, as determined from the top view and side view video cameras

11. Isothermal spreading of pure tin solder on the as-received copper surface at 280.0 $\pm 0.6^{\circ} \mathrm{C}$, as measured from the side view video data

12. Isothermal spreading of pure tin solder on the as-received copper surface for selected substrate temperatures

13. Arrhenius plot for the isothermal spreading of pure tin solder on the as-received copper surface in the temperature range from 262 to $331^{\circ} \mathrm{C}$ 
14. Optical micrographs of the edge of the tin-copper interface following the isothermal spreading of pure tin solder on the as-received copper substrate

15. Representative non-angle-resolved O 1s x-ray photoelectron spectra for copper surfaces studied in this work.

16. Representative normalized non-angle-resolved $\mathrm{Cu} 2 \mathrm{p}_{3 / 2} \mathrm{x}$-ray photoelectron spectra for copper surfaces studied in this work

17. Representative normalized non-angle-resolved $\mathrm{Cu}$ LMM x-ray photoelectron spectra for copper surfaces studied in this work

18. Illustration of the chemical species observed as a function of depth for each of the surface conditions studied. 


\section{Tables}

1. XPS Binding Energies (eV) for Surface Chemical Species.......................................... 29

2. XPS Sampling Depths $(\mathrm{nm})$ for Surface Chemical Species and Scans .......................... 35

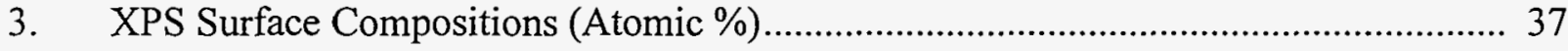




\section{Nomenclature}

AES Auger Electron Spectroscopy

$\mathrm{BE} \quad$ Binding Energy

DPCMA Double Pass Cylindrical Mirror Energy Analyzer

ELS Low Energy Electron Energy Loss Spectroscopy

ISS Ion Scattering Spectrometry

KE Kinetic Energy

PHI Perkin Elmer Physical Electronics

TPD Temperature Programmed Desorption

TPR Temperature Programmed Reaction

UHV Ultrahigh Vacuum

UPS Ultraviolet Photoelectron Spectroscopy

XPS X-ray Photoelectron Spectroscopy

A/V Audio/visual

B\&W Black and white

IR Infrared

NTSC National Television Standard Commission

RMA Rosin Mildly Activated

SVHS Super Video Home Systems

UV Ultraviolet

VHS Video Home Systems

a Monolayer thickness

A Area

C Circumference

d Sampling depth

E Electron kinetic energy

$\mathrm{E}_{\mathrm{a}} \quad$ Activation energy

g Gravitational acceleration

$\mathrm{k} \quad$ Reaction constant

$\mathrm{n} \quad$ Number of atoms in molecule

N Avogadro's number

$\mathrm{r} \quad$ Radius

$\mathrm{R} \quad$ Universal gas constant

$\mathrm{R}_{\mathrm{a}} \quad$ Arithmetic (center line) average roughness

$\mathrm{t} \quad$ Time

T Temperature

$\mathrm{T}_{\mathrm{dcm}} \quad$ Decomposition temperature

W Atomic or molecular weight

Page vii 
$\Delta \Phi \quad$ Work function change

$\gamma$ Interfacial tension between the liquid and gas (surface tension)

$\kappa^{-1} \quad$ Capillary length

$\lambda_{\mathrm{m}} \quad$ Electron mean free path in monolayers

$\lambda_{\mathrm{n}} \quad$ Electron mean free path in nanometers

$\rho \quad$ Bulk density 


\section{Kinetics of the Wetting of Tin on Air-Passivated Copper in the Absence of a Fluxing Agent}

\subsection{Introduction}

In general, when a droplet of liquid is placed on a wettable solid surface, it will initially undergo extremely rapid and dynamic spreading. The rate of spreading then slows and for many liquids the radius of the droplet expands as some power of the spreading time. De Gennes ${ }^{1}$ reviewed and amplified a simple calculation for the spreading of liquids on solids. This simple relation uses the parameters of liquid surface tension, liquid viscosity, equilibrium contact angle, and the volume of the liquid drop to determine the kinetics of spreading. If there is no interaction or coupling, other than van der Waals forces, between the liquid and solid phases, spreading should follow the kinetics evolved from de Gennes' model. In fact, spreading in many different kinds of non-interacting liquid-solid systems has been shown to conform with this kinetic model.

Since the values for viscosity $(0.015 \text { poise })^{2}$, surface tension $(460 \mathrm{mN} / \mathrm{m})^{3}$, and equilibrium contact angle $\left(15^{\circ}\right)^{4}$ are known for tin/lead eutectic solder, it follows that de Gennes' model should be useful in the prediction of solder spreading kinetics for engineering analysis of solder wetting in electronics manufacturing processes. However, this simple calculation is in error by many orders of magnitude relative to the spreading rates observed in an actual solder system. Figure 1 shows a comparison of the rate of spreading for tin/lead solder predicted from de Gennes' model to the actual spreading rate observed for Sn60Pb40 solder with Kester 197 RMA flux at $220^{\circ} \mathrm{C}$ on a solid copper substrate. The initial shape of the liquid solder on the substrate in each case is a spherical drop. De Gennes' model predicts that the solder will spread rapidly into a spherical cap configuration, reaching the equilibrium contact angle at about $1 \mathrm{msec}$ after the initiation of spreading (defined as the point when the contact angle is equal to $90^{\circ}$ ). However, experimental observation shows that approximately $50 \mathrm{sec}$ is required for the tin/lead solder drop to reach its equilibrium configuration. De Gennes' model differs from the experimental observation by a factor of $5 \times 10^{4}$. Clearly, the currently accepted spreading theories do not apply to systems like solder on a metal substrate. Factors have been left out of the force balance equation that dominate the solder dissipation function. The discovery and experimental verification of these excluded contributions (most likely surface chemical in nature) and the development of a quantitative description of these effects, is an important scientific challenge which will ultimately have a great impact on the practice of soldering in electronics manufacturing.

The model derived by de Gennes includes the assumption that the substrate does not dissolve or otherwise react with the spreading liquid droplet. However, it has long been recognized in the solder industry that partial substrate dissolution occurs during solder wetting on metal substrates and intermetallic formation is always observed in practical solder/substrate systems. In addition, the reactive surfaces present on the liquid solder and clean metal substrate are highly susceptible to contamination through adsorption, reaction and diffusion processes. In 
fact, the primary purpose of the fluxing agent commonly used in soldering processes is to remove existing surface oxides and prevent their reformation until after the solder joint is completed.

Figure 2 is taken from the model presented by Smith and Lea ${ }^{5}$, and illustrates the typical zones observed in the interfacial regions as a result of the interaction of tin/lead solder with a copper substrate. The dominant interaction observed between the solder and the substrate in metallographic cross sections is the dissolution and diffusion of copper into the tin/lead solder and the diffusion of tin from the solder into the copper substrate to form $\mathrm{Cu}_{6} \mathrm{Sn}_{5}$ and $\mathrm{Cu}_{3} \mathrm{Sn}$ intermetallics. This latter diffusion results in a tin-depleted region in the solder adjacent to the solder-copper interface. Surface energy minimization also leads to the enrichment of lead on the surface of the solder. Regions where surface oxides are present and must be removed are also noted in the figure. Each of these reaction and diffusion processes must be accounted for in

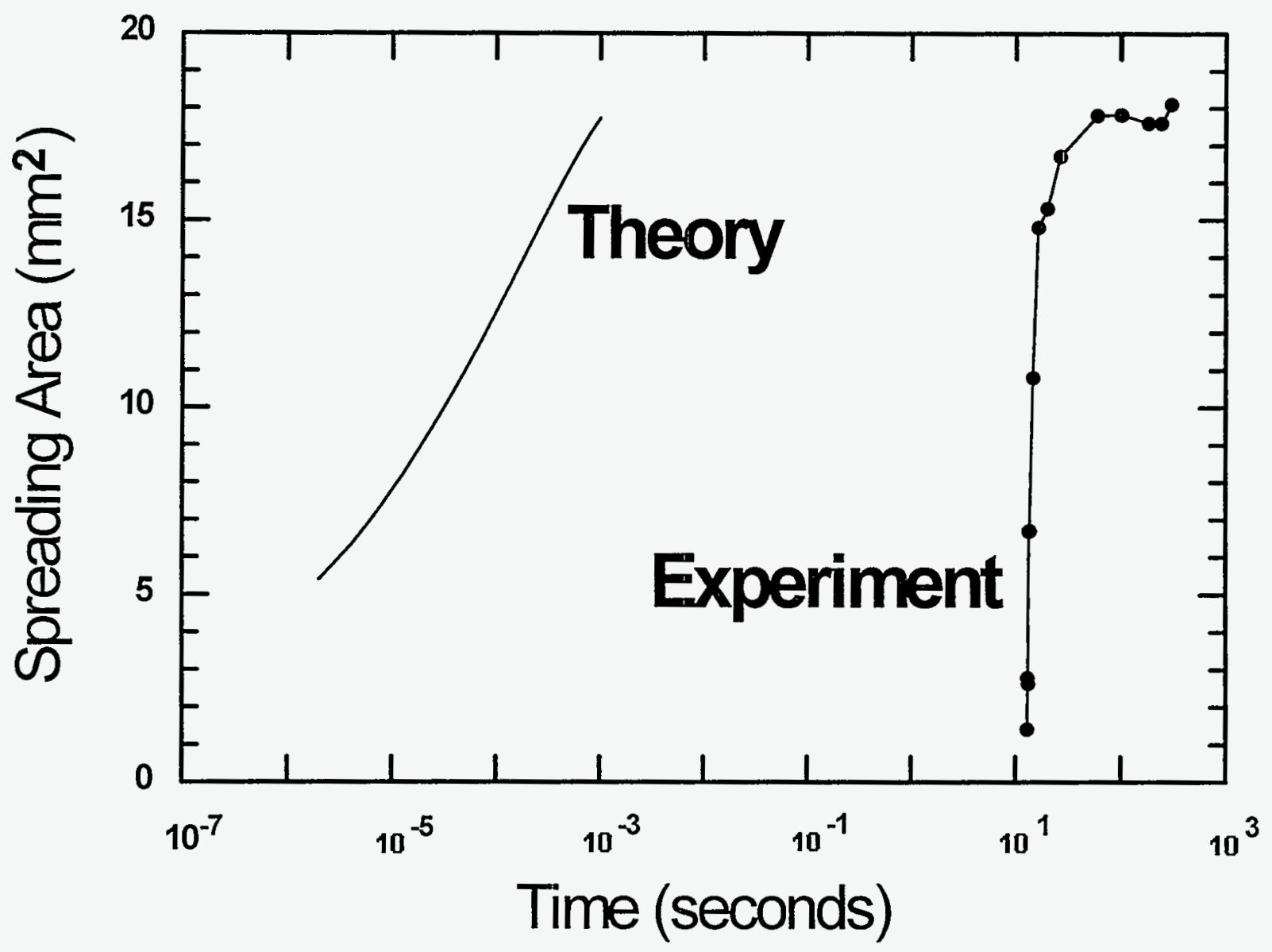

Figure 1: Comparison of experimental spreading kinetics of tin/lead solder to that predicted by de Gennes' theory using appropriate values of the viscosity and surface tension for the solder. The experimental spreading rate was obtained for Sn60Pb40 solder on a copper substrate using Kester 197 RMA flux. 
order to derive a complete model for the kinetics of spreading in reactive systems like solder on a metal substrate.

The problem of surface contamination and segregation exists as a common thread in past studies of the surface chemistry of liquids and solids. Because liquid wetting on solid surfaces is dominated by surface interactions, the chemistry of the liquid and solid surfaces, as well as the interface between the liquid and the solid, is of major importance. For liquids, numerous techniques have been developed to probe the equilibrium thermodynamic, visco-elastic and dynamic properties of surfaces, but a major concern has always been the absence of a well controlled surface composition. For solids, this same concern has led to an array of ultrahigh vacuum (UHV) techniques for the study of compositional, structural, electronic and dynamic properties of the solid surface. The use of UHV is demanded by contamination rates of the ambient atmosphere. The obvious need for enlightening new research in the area of liquid metal wetting on solid surfaces is a combination of the scientific approaches previously established in independent studies of the surface chemistry of liquids and solids. Electron spectroscopies

\section{Surface}

Enrichment Region

of $\mathrm{Pb}$ (oxide) of $\mathrm{Sn}$

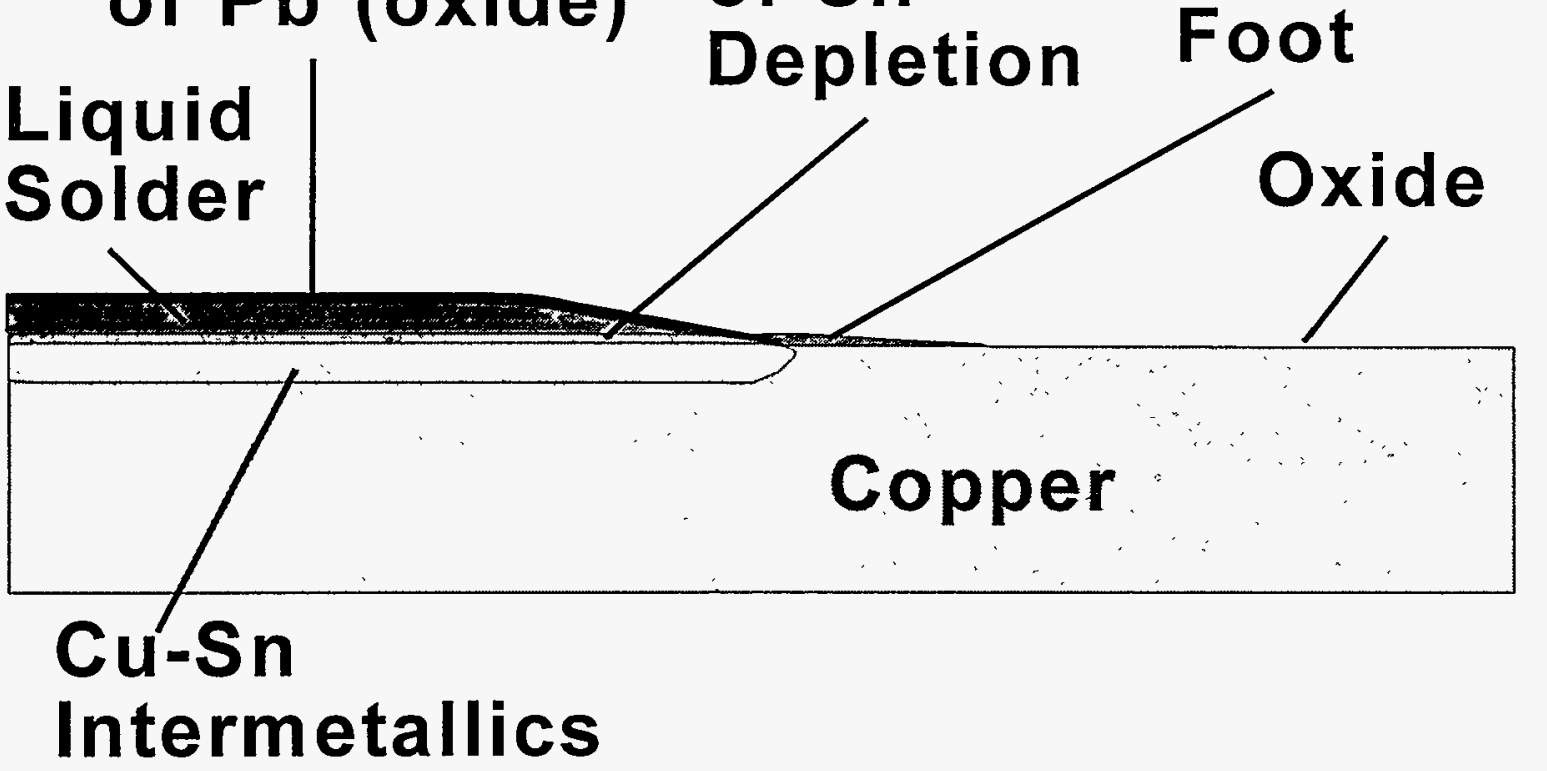

Figure 2: Illustration of some of the complex chemical interactions which occur for tin/lead solder spreading on an oxidized copper substrate. Taken from the model presented by Smith and Lea, ${ }^{5}$ this figure illustrates the typical zones which have been observed in the tin/lead-copper interfacial regions as a result of the soldering process. 
require relatively low sample vapor pressures to maintain UHV compatibility and some liquid metals (including tin/lead solder alloys over most of the alloy composition range) are compatible with this UHV requirement. The use of modern UHV surface analytical techniques allows full characterization of the surface composition and chemistry for both the solid substrate and the liquid metal. In addition, with the application of surface modification tools such as ion sputtercleaning and gas/surface chemical reactions for surface reduction or oxidation, highly controlled and well characterized surfaces may be prepared and utilized in spreading experiments.

The present work is designed to identify and quantify various surface processes and reactions that occur during the spreading of solder on metal substrates. A major goal of our initial experiments is to examine the effect of substrate surface oxidation on the kinetics of solder spreading on copper. The rate limiting step controlling the spreading of solder on metal surfaces is presently thought to be either the reaction of the solder with the (dissolving) substrate to form intermetallic compounds, or the reaction and removal of surface contaminants by the solder flux. However, the relative importance of surface contamination, metal atom diffusion, metal-metal oxide reactions, and flux reactions in the solder spreading process is not well understood. By investigating the spreading of solder on atomically clean and partially oxidized metal surfaces in the absence of a chemical flux, this study will isolate the interactions between the solder and the substrate from interactions involving the chemical flux. Complete characterization of each of the fundamental steps in solder spreading will lead to improved theoretical models for this important manufacturing process, facilitating the prediction of solder behavior in a variety of situations. Improved theoretical models should increase our ability to understand and solve existing solder wetting problems as well as to predict the behavior of solder and flux formulations in new soldering applications.

We also hope to gain, as a part of this study, an understanding of how much oxide needs to be present in order to significantly inhibit solder spreading. This knowledge will help establish how much gas-phase contamination (or time delay between cleaning and solder application steps) can be tolerated in the inert gas and fluxless soldering processes currently under development. Finally, a fundamental understanding of the processes involved in solder wetting and spreading should aid in the development of new surface passivation and protective layers leading to entirely new types of soldering processes.

This report summarizes initial studies of the isothermal spreading of tin on as-received copper surfaces and limited temperature ramp studies of the spreading of tin as a function of oxide thickness on the copper surfaces. Copper was chosen as the substrate material because of its wide use as a primary material for interconnects on electronic assemblies. Copper substrates were prepared and characterized in a specially designed in situ surface analysis system under conditions such that spreading experiments could be performed without exposure of the substrates to contamination from the laboratory environment. For a solder, we have chosen to perform these experiments using pure tin. Most solders presently employed in the electronics industry are tin/lead alloys, primarily at or near the $\mathrm{Sn} 63 \mathrm{~Pb} 37$ eutectic composition. In these solder alloys, tin is the reactive metal ingredient. Lead is added primarily to lower the melting temperature of the solder, but it also modifies the surface tension of the solder for improved wetting performance. It is the tin in the solder alloys that forms intermetallic compounds with 
the substrate for improved adhesion and mechanical behavior. In addition, the vapor pressure of pure tin remains well below $10^{-10}$ torr even at temperatures $300^{\circ} \mathrm{C}$ above the melting point, facilitating its use in UHV experiments. For these reasons, tin on copper forms an ideal model system to evaluate wetting behavior as a function of surface composition. By eliminating flux and lead in the model solder system, the number of processes that could possibly control wetting kinetics is significantly reduced.

The work described in this report represents the initial experiments in an ongoing research program to investigate the fundamental processes which control the wetting and spreading of solder on metal surfaces. Isothermal experiments are currently in progress to characterize the effect of decreasing oxide thickness on the kinetics of pure tin solder spreading on copper substrates. In addition, experiments are also in progress to investigate the kinetics of spreading of tin/lead solder alloys both in the absence and presence of a chemical flux in order to better understand the role of these process variables. 


\subsection{Experimental}

\subsection{In Situ Surface Analysis and Wetting System}

These experiments were performed in a system especially designed and constructed for the study of the effects of the surface chemical state on the kinetics of the wetting and spreading of liquid metals on solid surfaces. The basic system consists of two separate UHV chambers that are linked by an integral sample transport assembly. The system is illustrated schematically in Figure 3. The first chamber is designed for surface chemical analysis and surface modification. The second chamber is designed to study the wetting and spreading kinetics of liquid metals at elevated temperatures under a variety of ambient atmospheric conditions. The two chambers are linked and isolated by a UHV gate valve. Individual samples are mounted on a transportable sample stage which can be placed on a sample manipulator in either chamber. The sample stage is transferred between the two chambers by a fork mounted on a magnet-driven transport rod, allowing the sample to be prepared, analyzed and undergo reaction without intermediate exposure to contaminating atmospheres. The entire system is completely UHV compatible, and may be baked at $150^{\circ} \mathrm{C}$ to ensure system cleanliness and suitable

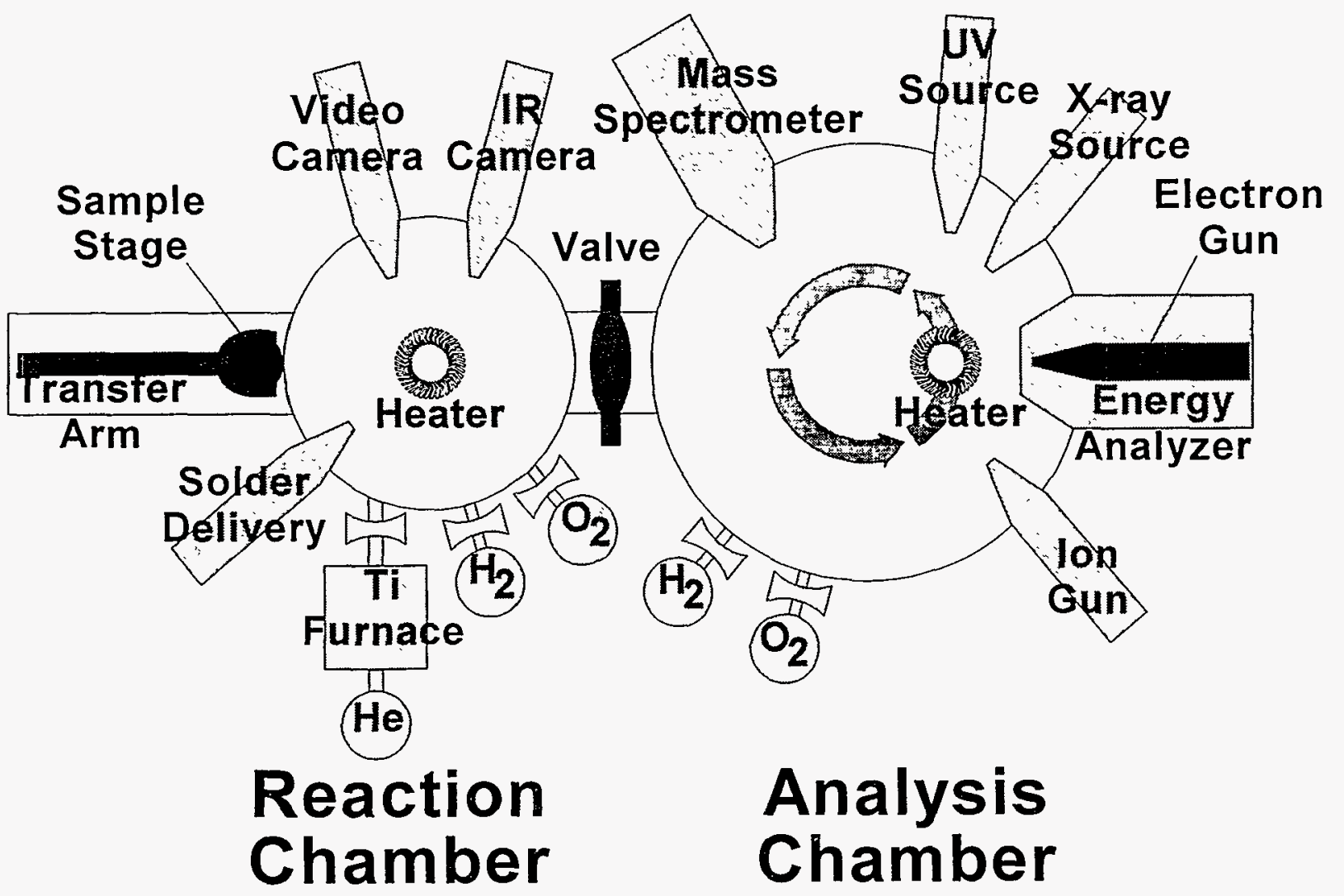

Figure 3: Schematic illustration of the In Situ Surface Analysis and Wetting System especially designed for the determination of the effects of surface chemical state on the kinetics of the wetting and spreading of liquid metals on solid surfaces. 
background pressure levels.

The analysis chamber is a standard UHV surface analysis chamber, modified from a basic Perkin Elmer Physical Electronics (PHI) 548 system. The chamber is pumped by a $300 \mathrm{l} / \mathrm{sec}$ ion pump with additional reactive gas pumping provided by a titanium sublimation pump. Base pressure for this system is typically $5 \times 10^{-10}$ torr in standby mode and $2 \times 10^{-9}$ torr with the electron and $\mathrm{x}$-ray sources running at full power. These pressures can be reduced by about $1 / 2$ order of magnitude with system bake out. As presently configured, the analysis chamber supports a wide variety of surface analytical techniques including: $\mathrm{x}$-ray photoelectron spectroscopy (XPS), ultraviolet photoelectron spectroscopy (UPS), auger electron spectroscopy (AES), low energy electron energy loss spectroscopy (ELS), ion scattering spectrometry (ISS), work function measurements $(\Delta \Phi)$, temperature programmed desorption (TPD) and temperature programmed reaction (TPR).

The analysis chamber contains $\mathrm{x}$-ray, ultraviolet and electron beam excitation sources for electron spectroscopic surface analysis. The x-ray generator system is a PHI 1248, using an 04-548 dual anode source. This $\mathrm{x}$-ray source is capable of switching between two different anode surfaces for photoelectron peak shifting or simultaneous operation of two identical anode surfaces for high output irradiance. For XPS, signal detection is by direct pulse counting through an EG\&G PARC 1182 amplifier/discriminator. The analysis area for XPS is about $2.5 \mathrm{~mm}$ diameter. The electron gun is a $5 \mathrm{kV}$ source that is integral to, and coaxial with, the energy analyzer. For AES, signal detection is by a PHI 96B voltage to frequency converter, operated in integral spectrum mode. The electron beam size for AES is $<100 \mu \mathrm{m}$. Electron/ion analysis is performed using a PHI 15-255 GAR doublepass angle-resolving cylindrical mirror energy analyzer (DPCMA) controlled by a PHI 20-810 digital analyzer controller. The average detection angle is about $45^{\circ}$ from the sample normal in non-angleresolved mode, although it varies with the degree of sample tilt ( $42.3^{\circ}$ for the sample normal coaxial to the DPCMA axis and $46.9^{\circ}$ for the sample normal $30^{\circ}$ off the DPCMA axis). The system is equipped with a PHI 04-303A $5 \mathrm{kV}$ differentially-pumped ion gun for the sputter cleaning of sample surfaces and ion-surface reactions. The differential pumping of the ionization chamber in the ion gun is provided by a Balzers TPU060 $50 \mathrm{l} / \mathrm{sec}$ turbomolecular pump. The ion gun is equipped with a multiple gas inlet manifold for rapid switching of process gases. A Balzers QMG420 quadrupole mass spectrometer with a cross-beam ionization source and off-axis electron multiplier detection is included in the analysis chamber for background and reaction gas analysis. Samples are held in a PHI 10-202 manipulator, which allows 3-axis linear translation and 2-axis sample rotation. The manipulator is equipped with an electron bombardment heater for in situ sample heating to $600^{\circ} \mathrm{C}$ using a PHI 20-028A heater control. Visual imaging of the sample and analysis area are provided by an Olympus OES borescope with coaxial metal halide lighting and microscopic imaging. Multiple gas inlets are provided on the chamber to allow low pressure reactive gas cleaning and chemical modification (such as oxidation or reduction) of the substrate surface in the analytical chamber. The system electronics are interfaced to a Gateway 2000 486DX2/50 computer, through the PHI 137/3027 interface and control electronics with user-written acquisition and analysis software. The same computer also controls the quadrupole mass spectrometer through Balzers Quadstar software.

The reaction chamber is designed specifically to facilitate wetting and spreading experiments under controlled atmospheres with dynamic real-time video monitoring of spreading kinetics. The reaction chamber also serves as a sample load lock, enabling rapid introduction and removal of 
samples from the system without bringing the analysis chamber up to air. The chamber is pumped by a Balzers TPU060 $50 \mathrm{l} / \mathrm{sec}$ turbomolecular pump which can achieve a base pressure of $1 \times 10^{-6}$ torr within minutes after introducing a sample into the chamber. Lower base pressures (down to about $3 \times 10^{-8}$ torr) may be obtained with extended pumping times. Supplementary reactive gas pumping is also provided by a titanium sublimation pump. The chamber contains a sample heating module which is identical to that contained on the manipulator in the analysis chamber. This heating module is mounted on a linear feedthrough for single-axis translation in the vertical direction to allow the module to be lowered out of the way when the transfer arm is moved into the analysis chamber. Although the sample on the manipulator in the analytical chamber is allowed to tilt through a wide angular range (including both horizontal and vertical positions) to facilitate surface analysis, the sample orientation on the heater in the reaction chamber is restricted to a horizontal mounting position in order to maintain the liquid metal under study on the surface of the sample. Multiple gas inlets are provided in order to allow reactive chemical modification of the surface at pressures up to atmospheric pressure, or to provide tailored ambient atmospheres during wetting and spreading experiments. The reaction chamber is provided with one special gas inlet, through which inert gases (typically research grade helium) are introduced into the system after purification with a Thermal Technology IGP-1A titanium furnace inert gas purifier, operated at $800^{\circ} \mathrm{C}$. A zirconia tube oxygen detector is used to monitor the purity of the inert gas effluent from the purifier. The internal plumbing of this commercial titanium furnace purifier was modified to provide all welded stainless steel joints. External connections were converted to Cajon VCR fittings. With these modifications, this gas purifier is capable of removing oxygen from an inert gas feed stream to concentrations below the part-per-billion level, thereby allowing the use of very high purity inert gas atmospheres in the reaction chamber during spreading experiments. Ambient gas pressures in the reaction chamber are measured by 10 and 1000 torr MKS 221A capacitance manometer gauges. A special solder delivery device has been constructed for this system, consisting of a pair of needle-point tweezer jaws mounted on a rotary/linear/tilt feedthrough (Huntington VF-176-4-R, modified jaw style C). The feedthrough assembly contains an additional rotary feedthrough for opening and closing the tweezer jaws. The surfaces of the tweezer jaws have been thoroughly passivated by baking in air, such that molten solder will not wet or adhere to them. By external manipulation of the feedthrough, the tips of the tweezers are positioned as desired on the sample surface for delivery of solid or molten solder to the surface. Dynamic real-time video monitoring of the spreading of the molten solder on the surface is provided by two video cameras, one looking down at the top of the sample and one providing a side view of the sample. The video setup is described in section 2.4.

\subsection{Materials Preparation}

\subsubsection{Pure Tin Solder Balls}

Balls of pure tin were prepared by punching disks of tin out of $0.127 \mathrm{~mm}$ thick $99.999 \%$ pure tin foil using a $4.88 \mathrm{~mm}$ diameter tool. To form spherical balls, each of these disks was melted in a bath of about $20 \mathrm{ml}$ Kester $197 \mathrm{RMA}$ flux at a temperature of approximately $260^{\circ} \mathrm{C}$. The flux bath was then cooled to a temperature where the tin had solidified, but the flux remained semi-solid. At this point, the spheres were removed from the flux and cleaned by immersion in acetone overnight or until flux residues were no longer visible. The tin balls were rinsed in methanol, air dried, and stored 
under laboratory air in sealed containers until ready for use. The diameter of the prepared pure tin solder balls was approximately $1 \mathrm{~mm}$ before spreading on the substrate.

Prior to use in an experiment, each tin solder ball was washed for 5 minutes in a $2 \%$ solution of Micro alkaline laboratory cleaner (Cole-Parmer Instrument Company, Chicago, Illinois) to etch away surface oxides and other surface contamination. After rinsing in water for 5 minutes, the solder ball was washed for 5 minutes in acetone followed by a 5 minute wash in isopropanol. All of these washes were performed at room temperature by immersing the tin ball in a beaker filled with about $25 \mathrm{ml}$ of solvent with periodic agitation. Following cleaning, the tin solder ball was allowed to dry for $30 \pm 10$ minutes in room air. After drying, the solder ball was weighed to determine the exact amount of tin present in the ball. Immediately after weighing, the solder ball was placed in the reaction chamber and the chamber pumped down to $<2 \times 10^{-6}$ torr. The pure tin solder balls used in this study weighed an average of $16.6 \pm 0.5 \mathrm{mg}$.

\subsubsection{Copper Substrates}

The copper substrates were prepared from $99.999+\%$ pure copper sheet. Samples $15 \mathrm{~mm}$ square were cut from $0.25 \mathrm{~mm}$ thick copper sheet. Each sample was engraved with a sample identification number on the back of the sample and then flattened by rolling between a metal cylinder and a flat metal plate while sandwiched between sheets of lint-free cloth. The copper substrates were then degreased by immersing lots of about 30 samples in a beaker with about $50 \mathrm{ml}$ of acetone for 5 minutes with periodic agitation followed by immersion in isopropanol for 5 minutes. After air drying, the samples were stored under laboratory air in sealed containers until ready for use. Representative substrates were profiled for surface roughness with a Veeco Dektak 8000 Surface Profilometer using a $2.5 \mu \mathrm{m}$ diameter tip at $20 \mathrm{mg}$ normal force, a vertical step resolution of $4 \mathrm{~nm}$, and a horizontal step resolution of $2.5 \mu \mathrm{m}$. The arithmetic average roughness value $\left(\mathrm{R}_{\mathrm{a}}\right)$ was measured for three different samples ( 6 measurements per sample), yielding an average value of $122 \pm 68 \mathrm{~nm}$. The copper surfaces show isotropic roughness, with no preferred direction for scratches or irregularities. All copper substrates were mounted on a molybdenum sample stage for transport into the vacuum system. A $0.25 \mathrm{~mm}$ diameter chromel/alumel (type $\mathrm{K}$ ) thermocouple junction was placed between the copper substrates and the molybdenum sample stage for temperature measurements, except where noted otherwise.

\subsection{Experimental Procedures}

A number of different experimental procedures were followed in this study, depending upon the objective of the experiment. These procedures are detailed below.

\subsubsection{Helium Pressure Dependence Measurements}

Experiments were performed to determine the optimum ambient pressure of helium necessary to produce close thermal coupling between the copper substrate and a solder ball setting on the surface of the substrate during solder spreading experiments. For these experiments, a tin solder ball was prepared and placed in the center of the copper sample after the substrate was loaded into the

reaction chamber. The reaction chamber was pumped down to a pressure $<2 \times 10^{-6}$ torr, and 
backfilled with oxygen-free helium to bring the pressure up to the desired value. The substrate was then ramped up linearly in temperature at a rate of $3^{\circ} \mathrm{C}$ per second. The heating profile of the sample stage at each helium pressure was adjusted to assure that the temperature ramp was constant as a function of helium pressure. The form and shape of the solder ball on the surface of the substrate was monitored by video cameras during the course of the temperature ramp. The resulting video tapes were then examined to determine the apparent melting temperature of the solder ball relative to the substrate surface as a function of helium pressure. Melting of the solder ball in the video images was normally indicated by a smoothing of imperfections initially present on the solder ball due to chemical etching and by a distinct transition of the solder ball to a more spherical geometry.

\subsubsection{Temperature Ramp Spreading Experiments}

A number of solder spreading experiments were performed with a nearly linear temperature ramp, in order to determine the threshold temperature for spreading of pure tin solder on copper substrates as a function of a variety of the substrate surface conditions. For spreading experiments performed on the as-received substrate surface, no additional surface preparation was performed beyond the degreasing step described in section 2.1.2 above. The tin solder ball was placed in the center of the copper substrate after the substrate was loaded onto the heating stage in the reaction chamber but before the reaction chamber door was sealed. For spreading experiments performed on the sputter-cleaned substrate surface, the copper substrate was loaded into the analytical chamber and ion sputter-cleaned over a $10 \mathrm{~mm}^{2}$ area for 30 minutes using $3 \mathrm{keV}$ Ar ions. The ion gun was operated at a pressure of $1 \times 10^{-4}$ torr in the ion gun ionization chamber and an emission current of $25 \mathrm{~mA}$. The air-exposed substrate surface was prepared by ion sputter-cleaning of the substrate surface as described above, followed by a 5 minute air exposure at atmospheric pressure and $25^{\circ} \mathrm{C}$ in the reaction chamber. The reaction chamber was pumped down to a pressure $<2 \times 10^{-6}$ torr immediately after the air exposure. For the sputter-cleaned sample, temperature monitoring during the ramp experiment via thermocouple was not possible, since the experimental system is not designed to allow transfer of the thermocouple into the analysis chamber along with the sample. For experiments involving this surface condition, temperatures were estimated from the time of heating, using a second-order polynomial fit of temperature versus time data taken from four different temperature ramp experiments measured with a thermocouple under otherwise identical experimental conditions. In future experiments, an infrared camera system will be used to directly monitor surface temperatures for all experiments where a thermocouple cannot be used. For the air-exposed substrate, the thermocouple was mounted under the sample during the brief air exposure. For all experiments involving the sputter-cleaned and air-exposed substrate surface conditions, the solid tin solder ball was initially mounted in the solder delivery device at the same time as the copper substrate was loaded into the reaction chamber. After preparation of the substrate surface as described above and placement of the substrate onto the heating stage in the reaction chamber, the solder ball was placed in the center of the substrate using the solder delivery device while the substrate was still under vacuum.

After preparation of the substrate surface and placement of the solder ball at the center of the substrate, the reaction chamber was backfilled with oxygen-free helium to a final pressure of 50 torr for all spreading experiments. The substrate was then ramped up linearly in temperature at a rate of $3^{\circ} \mathrm{C}$ per second. The shape and time dependence of the solder spreading on the surface of the 
substrate was recorded by video cameras during the course of the temperature ramp. The resulting video tapes were then analyzed to determine the area of solder spreading as a function of time and substrate temperature.

\subsubsection{Isothermal Spreading Experiments}

A series of experiments were performed under isothermal spreading conditions in order to accurately determine the kinetics of solder spreading as a function of sample temperature. In these isothermal experiments, only the as-received surface condition was investigated, using a thermocouple for the measurement of substrate temperature. After the copper substrate was loaded into the reaction chamber and the tin solder ball was loaded into the solder delivery device, the reaction chamber was pumped down to a pressure $<2 \times 10^{-6}$ torr and the reaction chamber backfilled to a final pressure of 50 torr. The temperature of the copper substrate was then ramped up to $300^{\circ} \mathrm{C}$ and allowed to cool and stabilize at the desired temperature for the experiment. Preheating of the copper substrates to $300^{\circ} \mathrm{C}$ was performed in order to ensure that the surface condition of the substrate was identical for all runs, i.e. that any surface modification resulting from reaction, diffusion, or desorption would occur to the same extent in all samples used in the isothermal spreading experiments. Experiments performed above $300^{\circ} \mathrm{C}$ (added at the end of this data series) were performed by heating up the substrate directly to the desired temperature.

After stabilization of the substrate temperature at a constant value, the tin solder ball was positioned about $0.5 \mathrm{~mm}$ above the center of the copper sample. In this position convective heating from the hot substrate resulted in melting of the tin within 10 seconds and preheating of the solder ball to a temperature near the substrate temperature. After approximately 1 minute, the molten solder ball was dropped down onto the substrate surface by separating the jaws of the tweezers. The shape and time dependence of the solder spreading on the surface of the substrate were recorded by video cameras and the resulting video tapes were analyzed to determine the initial rate of spreading for each substrate temperature. The substrates were immediately cooled to $<30^{\circ} \mathrm{C}$ (requiring about 30 minutes at 50 torr helium) before pumping out the helium and bringing the reaction chamber up to air. A number of samples were recovered after the isothermal spreading experiments for metallographic cross sectioning and examination.

\subsubsection{Surface Composition and Chemistry Measurements}

The surface composition and chemistry of the copper substrates was investigated for all of the surface conditions used for spreading experiments in this study. Samples were prepared for asreceived, sputter-cleaned, and air-exposed surface conditions using the procedures described in section 2.3.2 above. After preparation, each sample was transferred into the analytical chamber for examination by XPS. For each sample, spectra were acquired in non-angle-resolved mode (designated as a normal scan) and in angle-resolved mode using a $90^{\circ}$ polar aperture angle with photoelectron data collection at an average detection angle of $18.7^{\circ}$ from the sample normal for "bulk" measurements (designated as a bulk scan) and $70.3^{\circ}$ from the sample normal for "surface" measurements (designated as a surface scan). These angles represent the minimum and maximum average detection angles relative to the sample normal for our hardware configuration using a sample tilt angle of $30^{\circ}$. Some data was also acquired at a detection angle of $51.3^{\circ}$, between the surface and 
bulk scans (designated as a mid-depth scan). All spectra were acquired using a dual aluminum anode source $(1486.6 \mathrm{eV})$ operated at $15 \mathrm{kV}$ and $600 \mathrm{~W}$. Spectra were acquired for Survey, C 1s, O 1s, $\mathrm{Cu} 3 \mathrm{~s}, \mathrm{Cu} 2 \mathrm{p}$ and $\mathrm{Cu} \mathrm{LMM}$ regions simultaneously by performing consecutively one scan in series for each region. Each spectrum was acquired using $50 \mathrm{eV}$ pass energy, collecting data for $50 \mathrm{~ms}$ at each $0.1 \mathrm{eV}$ step, except for the Survey region, which was acquired using $100 \mathrm{eV}$ pass energy, collecting data for $50 \mathrm{~ms}$ at each $1.0 \mathrm{eV}$ step. Normal spectra were collected by summing 25 scans for each region, while 250 scans were summed for each region for angle-resolved spectra. Total acquisition time for a complete set of normal spectra was about 1 hour, while about 10 hours were required to obtain a complete set of angle-resolved spectra (spectra for all regions at one collection angle).

Each spectrum was digitally processed to calculate surface compositions and reduce the noise and artifacts present in the spectrum. A linear background and contributions arising from extraneous $x$-ray satellites were subtracted from each spectrum. Each spectrum was then smoothed using a Savitzky-Golay convolution procedure ${ }^{6-8}$ of quadratic/cubic order with 21 averaging points. Binding energies were referenced by setting the $\mathrm{C} 1 \mathrm{~s}$ peak energy to $284.7 \mathrm{eV}$, appropriate for adventitious hydrocarbons (i.e. adsorbed hydrocarbon species) on the surface. ${ }^{9}$ All spectra for a given surface condition (i.e. collected at the same time) were shifted by the energy necessary to set the $\mathrm{C} 1 \mathrm{~s}$ peak to $284.7 \mathrm{eV}$. However, for the bulk scan of the sputter-cleaned surface, use of this procedure led to binding energies for metallic copper which were $0.5 \mathrm{eV}$ higher than the expected values relative to the other observed binding energy values. Since adsorbed hydrocarbon species should not be present on the sputter-cleaned surface, use of the $284.7 \mathrm{eV}$ value for binding energy calibration on this surface is not appropriate. Consequently, for the bulk scan of the sputter-cleaned surface, binding energies were corrected by setting the $\mathrm{Cu} 2 \mathrm{p}_{3 / 2}$ peak to the value expected for clean copper, $932.2 \mathrm{eV}$. Peak areas were determined by integrating the area under the respective peaks above the linear baseline. Sample compositions were determined by assuming homogeneous distributions of all observed species both across the surface and in depth, using standard handbook sensitivity factors. ${ }^{9}$ All surface compositions are reported in atomic percentage values. For the comparison plots presented in this paper, some of the peaks were normalized by dividing the intensities by the measured peak areas in order to better compare the relative peak shapes. Oxide thicknesses were determined by comparing the surface composition to the average sampling depth for each surface condition.

\subsection{Video Monitoring and Image Analysis}

Figure 4 shows a schematic illustration of the video setup used to monitor real-time spreading of the tin solder in the reaction chamber. Three separate video CCD cameras were used: one to monitor the top view of the sample stage (color Panasonic WVCL700 with 18-108/f 2.5 zoom lens), one to monitor the side view of the sample stage (B\&W Sony SSC-D5 with 18-108/f 2.5 zoom lens), and one to monitor the thermocouple temperature readout (B\&W Sony SSC-D5 with 75/f 1.3 lens). All of the cameras were synchronized through a distribution amplifier (Kramer VM-10A) from a single black-burst sync source (Bio-electronics SG-2B sync generator). The video signal from the temperature readout was combined with a blank video signal generated from the sync source through splitter/inserter A (AD 1470A). This insertion provided a blank video signal with the temperature readout inserted into a small portion of the frame. This combined video signal was then fed through the interval timer (FOR-A VDA-206S video timer), producing a video signal with both temperature 
and time readouts inserted into the frame. The combined output from the interval timer was merged with the video signal from the side view camera through splitter/inserter B (AD 1470A) and then passed to the side view video recorder (JVC BR-S611U SVHS). The combined output from the interval timer was also merged with the feed from the top view camera through an $\mathrm{A} / \mathrm{V}$ mixer (Panasonic digital WJ-MX12) and then passed to the top view recorder (JVC BR-S811U SVHS) through a character generator (Knox K40S microfont). This configuration allows maximum magnification of the image from both the side and top view cameras, while maintaining strict synchronization, reference timing and temperature information between the views. Consequently, frames from both the side and top view camera outputs may be paired in time, to within a single video frame (1/30 of a second). An example of the final video output from the two sample stage cameras is shown in Figure 5. The addition of the character generator in the video circuit allows the direct addition of title labeling on both video recorders simultaneously.

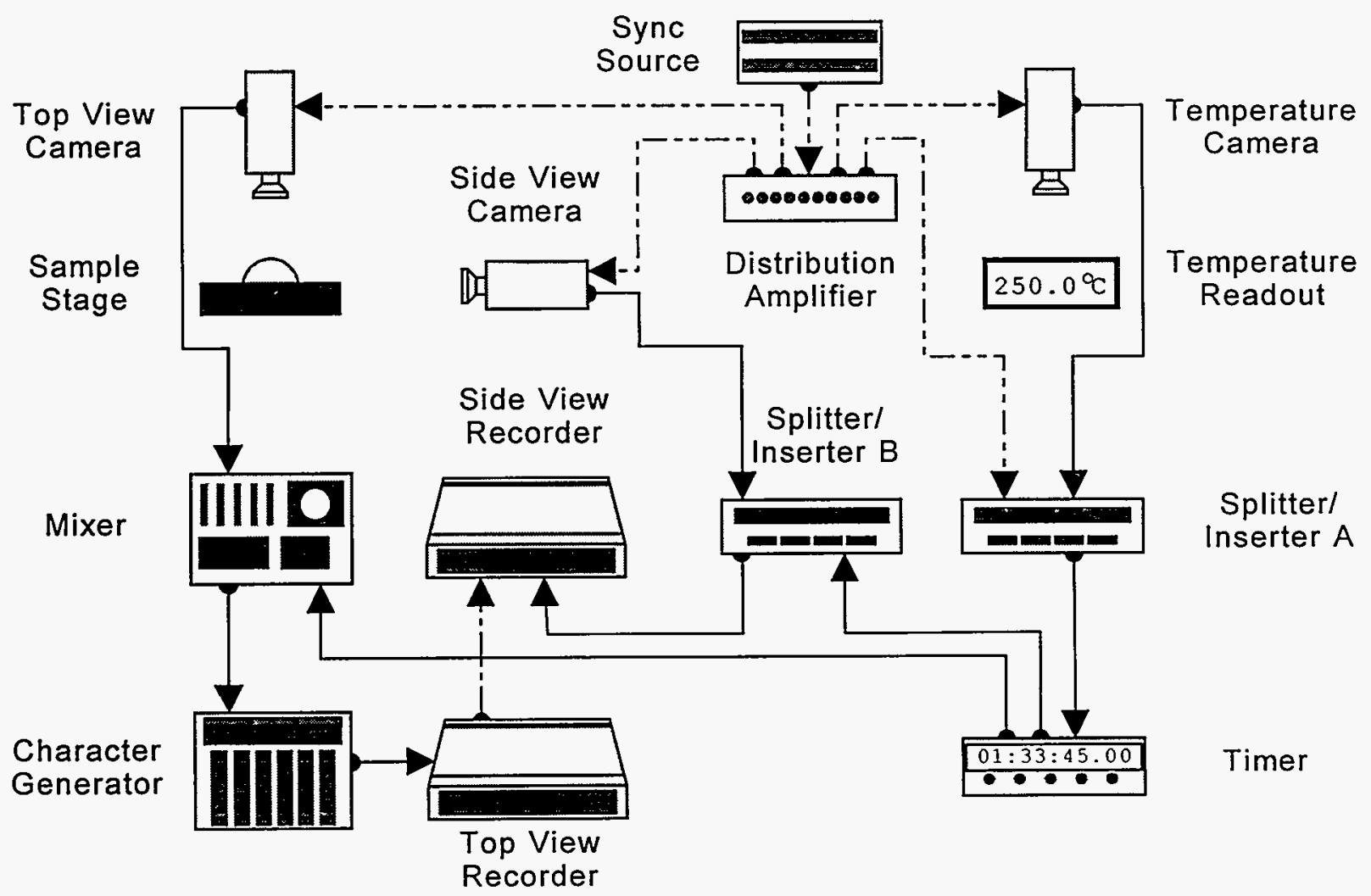

Figure 4: Schematic illustration of the setup used for the collection of video information during the real-time monitoring of solder spreading. See section 2.4 text for a detailed discussion. The dashed lines (----) in the figure indicate camera field of views. The solid lines $(\longrightarrow)$ represent video signal paths. The long-dash short-dash short-dash lines (---) represent electronic sync signals. The long-dash short-dash line (-_-) denotes the optional video link between the recorders. 
After acquisition, quantitative data was extracted from the video tapes using image analysis software (JAVA, by Jandell Scientific). Distance and area were calibrated with the software for each individual run by use of a "calibration screw" of measured diameter that was always held in the field of view of both the top view and side view cameras. This screw was scribed for reference so that the same screw was always used for calibration. After calibration, analysis of individual video frames was performed at selected time intervals depending on the total spreading time, in order to give similar data point densities for all experimental data sets. From the top view video data, time, temperature, area of spread, and the circumference of the area of spread were recorded for every point. From the side view video data, time, temperature, and the apparent diameter of the area of spread were recorded for every point. Direct measurements of the area and circumference from the top view camera were preferred for spreading rate measurements, since no assumptions were necessary concerning the shape of the spreading drop. However, due to obscuring of the true spreading area by the solder ball at very short times following the initial contact between the solder ball and the substrate (see section 3.3) as observed by the top view camera, and due to increased glare from the lighting system when the drop was near its initial spherical shape, much more accurate data was obtained for initial spreading rates using the diameter measured from the apparent length of the tin/copper interface taken from the side view camera. Area and circumference were then calculated from this diameter measurement, assuming that the drop was spreading in a true circular geometry. Rate of spreading measurements taken from the side view camera in this way were used only in the analysis of the isothermal experiments.

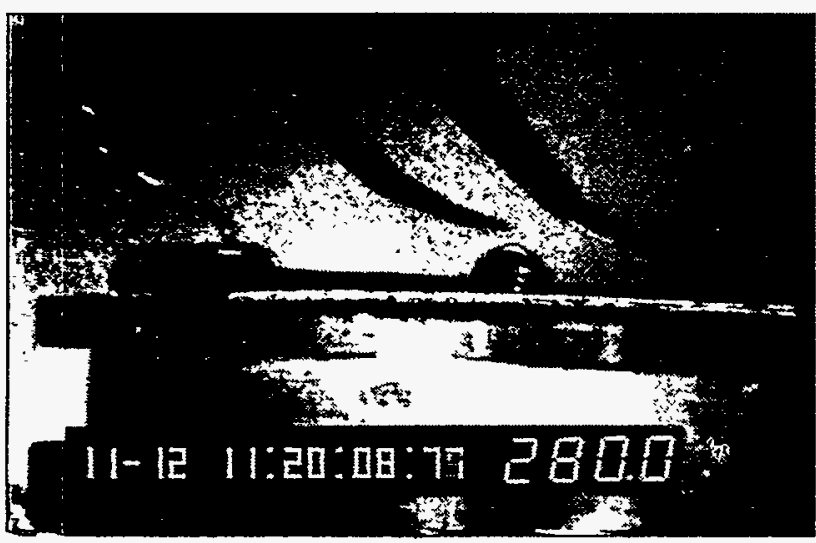

Side View

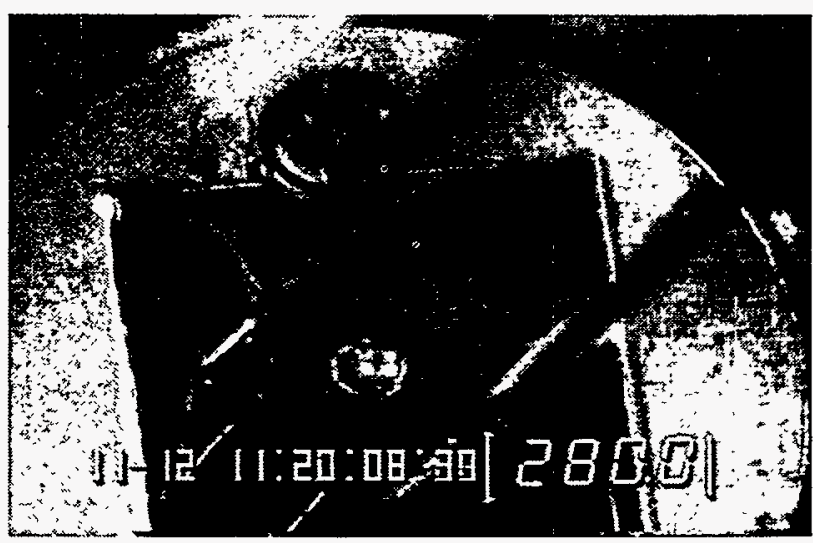

Top View

Figure 5: Examples of side view and top view video frames shortly after dropping a tin solder ball onto a copper substrate at $280.0^{\circ} \mathrm{C}$. The digital display inlayed on the lower right of each frame indicates the sample temperature, while the digital display inlayed on the lower left of each frame shows the output of the interval timer. The tweezer tips in the frames are a part of the solder delivery device. A thermocouple whose junction is inserted between the copper substrate and the molybdenum sample carrier may be seen coming from the left side of the substrate in the side view frame and off the top of the substrate in the top view frame. The screw head used for video image size calibration is $4.0 \mathrm{~mm}$ in diameter, and can be seen on the left of the side view frame and at the top of the top view frame. 


\subsection{Results and Discussion}

\subsection{Ambient Pressure Dependence Experiments}

Early in this study, it was noted by observing the apparent melting temperature during temperature ramp experiments of a spherical pure tin solder ball setting in direct contact with an asreceived copper substrate under a high vacuum environment, that the true temperature of the solder ball lagged behind the substrate temperature by over $40^{\circ} \mathrm{C}$. A spherical ball setting on a planar surface has a very limited area of contact between the ball and the underlying substrate. Thermal conduction through this contact area in a high vacuum environment was found to be too slow and inefficient to provide close thermal coupling between the solder ball and the substrate for our experimental configuration, at least at early times during a spreading experiment. As a result, any measurement of initial solder spreading rate performed under vacuum conditions could be seriously compromised by the temperature anisotropy existing between the solder ball and the substrate. In addition, in the high vacuum environment the sample heater and stage form a nearly adiabatic system, isolated from heats sinks. Consequently, the temperature of the sample stage is difficult to control under these conditions and the heating rates are affected by endothermic processes such as the melting of the solder ball on the surface.

In order to improve the thermal coupling between the solder ball and the substrate, helium gas was added to the ambient atmosphere to provide a method for convective heating of the solder ball by the substrate. Helium was chosen as the best ambient gas for this application due to its very high thermal conductivity and the ease with which it can be processed to a high degree of purity. The apparent melting temperature of pure tin solder balls on as-received copper substrates was measured as a function of ambient helium pressure in temperature ramp experiments using a constant ramp rate of $3^{\circ} \mathrm{C} / \mathrm{sec}$ (see section 2.3.1). The heating profile of the sample stage was adjusted at each helium pressure to assure a constant temperature ramp as a function of helium pressure. The results are presented in Figure 6. The apparent melting temperature of the pure tin solder balls drops rapidly during the addition of the first 10 torr of helium to the reaction chamber and then asymptotically approaches the nominal melting temperature for pure tin $\left(232^{\circ} \mathrm{C}\right)$. The addition of helium to the reaction chamber brings with it an increased potential for contamination of the substrate surface due to surface adsorption of reactive contaminants in the helium gas. Therefore, even though the apparent melting temperature of the tin solder balls remains a few degrees above the nominal value due to incomplete thermal coupling, a helium pressure of 50 torr was chosen for use in all further solder spreading experiments in this study. Based on the data presented in Figure 6, this helium pressure provides for adequate thermal transfer between the solder ball and the substrate while minimizing the exposure of the substrate surface to reactive contaminants in the ambient gas.

In order to ensure that no significant gas phase contamination problem was created in the solder spreading experiments due to the presence of 50 torr of helium in the reaction chamber, adsorption experiments were conducted by exposing a sputter-cleaned copper substrate to this ambient atmosphere for 30 minutes and for 2 hours, both at room temperature. At the end of each exposure period, no significant sulfur or chlorine contamination was detected on the substrate surface by XPS. However, small amounts of carbon $(\approx 5 \%)$ and oxygen $(\approx 6 \%)$ did accumulate on the surface during these exposures. The levels of carbon and oxygen contamination were essentially 
identical for both exposure times, suggesting that a thin layer of contaminant gases is adsorbed fairly rapidly, but this exposure passivates the surface for any further adsorption within this time frame. The levels and types of contamination observed are typical of saturation coverage of gases like $\mathrm{CO}$ and $\mathrm{H}_{2} \mathrm{O}$, which are often present in small amounts in vacuum ambients, due to desorption from the chamber walls. Using the sampling depths given for each peak in section $3.5\left(\mathrm{~d}_{\mathrm{C}}=7.3 \mathrm{~nm}\right.$ and $\left.\mathrm{d}_{\mathrm{O}}=6.5 \mathrm{~nm}\right)$ and the properties of bulk copper $\left(\rho=8.92 \mathrm{~g} / \mathrm{cm}^{3}\right.$ and $\mathrm{W}=63.55 \mathrm{~g} /$ mole $)$, these composition values represent about $3 \times 10^{15}$ atoms $/ \mathrm{cm}^{2}$. Using the atomic monolayer thickness $(a=0.23 \mathrm{~nm})$ calculated for copper as described in section 3.5 , the surface density is about $2 \times 10^{15}$ atoms $/ \mathrm{cm}^{2}$ for each monolayer of copper. These results suggest that the coverage of contaminant species is very near a single complete monolayer after these exposure conditions, if all of the contaminants are located on the sample surface rather than being distributed throughout the sample bulk material. Another exposure test was conducted in 50 torr helium with the sputter-cleaned sample heated to $300^{\circ} \mathrm{C}$ for 30 minutes. At the conclusion of this exposure, the sample showed minimal oxygen contamination $(\approx 2 \%)$ and significant carbon contamination $(\approx 40 \%)$ by XPS. These numbers suggest that the oxygen contamination is less than a complete monolayer coverage, while the carbon contamination is probably on the order of 3-5 monolayers in thickness, if all of the

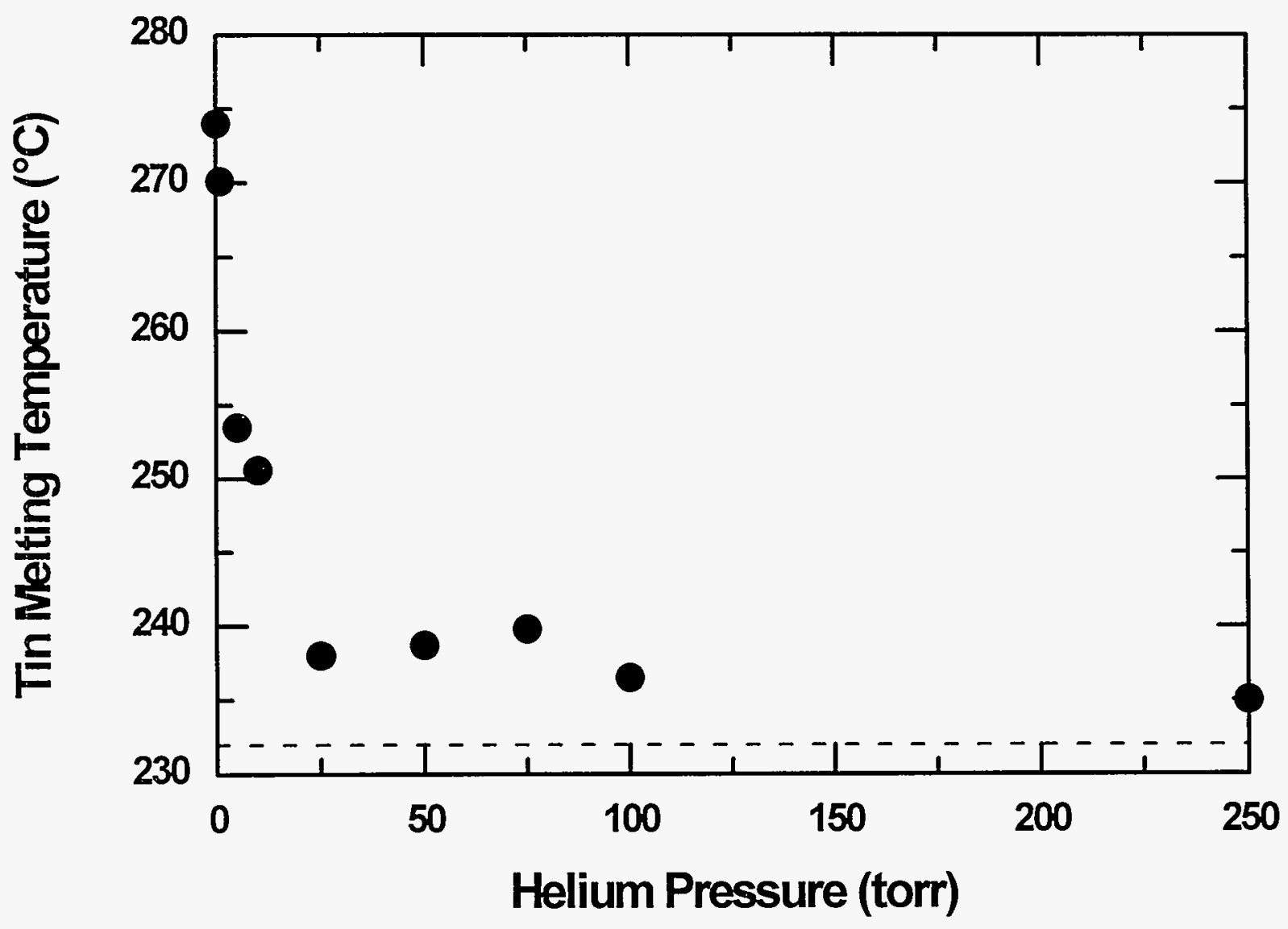

Figure 6: Apparent melting temperature of pure tin solder balls on as-received copper substrates as a function of ambient helium pressure in the reaction chamber. The dashed line shows the nominal melting temperature for pure tin $\left(232^{\circ} \mathrm{C}\right)$. 
contaminants are located on the sample surface rather than being distributed throughout the sample bulk material. Clearly, much more surface contamination is the result of the surface segregation of impurities dissolved in the copper substrate (especially carbon), rather than adsorption of reactive contaminants from the helium ambient.

\subsection{Temperature Ramp Spreading Experiments}

Spreading experiments for pure tin solder balls on the as-received, air-exposed and sputtercleaned copper surfaces were performed under 50 torr of purified helium with a nearly linear temperature ramp in order to determine the initiation temperature for solder wetting on these surfaces. As stated in section 2.3.2, a thermocouple could not be used for temperature measurements on the sputter-cleaned copper substrate due to the fact that this substrate had to be transferred into the analytical chamber for surface preparation with no subsequent air exposure. Consequently, for this sample, temperatures were estimated from the time of heating by using a second-order polynomial fit of temperature versus time data taken from four different temperature ramps measured with a thermocouple under otherwise identical experimental conditions. The results of this polynomial fit are shown in Figure 7. The solid symbols in the figure show the average temperature measured from the four temperature ramps at specific heating times after initiation of the ramp. The error bars in the figure give the standard deviation in these average temperature values. The solid line in the figure shows the polynomial function used to predict sample temperatures for the ramp experiment where a thermocouple could not be used. The sample heating rate is about $2.9^{\circ} \mathrm{C} / \mathrm{sec}$ in the first-order dependence. The ramp is quite linear from about 50 to $350^{\circ} \mathrm{C}$. The error bars show the standard deviation for the uncertainty in the temperature estimate of $\pm 3^{\circ} \mathrm{C}$ at $100^{\circ} \mathrm{C}, \pm 7^{\circ} \mathrm{C}$ at $200^{\circ} \mathrm{C}, \pm 11^{\circ} \mathrm{C}$ at $300^{\circ} \mathrm{C}$, and $\pm 13^{\circ} \mathrm{C}$ at $400^{\circ} \mathrm{C}$.

Results from the temperature ramp spreading experiment for pure tin solder on the as-received copper surface are shown in Figure 8. For this experiment, the substrate temperature was measured directly by a thermocouple inserted between the copper substrate and the molybdenum sample stage. The solid symbols in the figure show the apparent area of spread of the solder ball measured from the top view video image. Superimposed on the figure are drawings of the shape of the tin solder drop as a function of time/temperature at each portion of the wetting curve. Initially, the tin solder ball is solid and has a slightly flattened bottom as a result of the ball-formation process. A rough texture is easily observable on the solder ball surface as a result of the chemical etching performed during the cleaning process. The vertical line in the figure shows the temperature where melting of the solder ball is observed $\left(246^{\circ} \mathrm{C}\right)$. Analysis of video images taken from the side view camera shows a sharp transition in the shape of the solder ball at this temperature from a rough, flat-sided sphere with a dull surface finish to a smooth, shiny ball with a near perfect spherical shape. A decrease in the apparent diameter of the contact area under the solder ball was observed in the side-view video images upon melting of the solder ball, indicating that the molten solder did not wet the as-received copper surface at $246^{\circ} \mathrm{C}$. At $325^{\circ} \mathrm{C}$, the tin solder begins to wet the air-passivated copper surface and a decrease in the apparent area of the solder ball as measured from the top-view video image is observed. This decrease in the apparent area of the solder ball is the result of a change in the geometric shape of the ball. As the tin solder begins to wet the copper substrate, the empty volume under the ball fills in as the drop transforms to a "haystack" hape, resulting in a decrease in the diameter of the drop. At $340^{\circ} \mathrm{C}$, a sharp increase in the area of spread of the solder drop is observed. The geometry of the 
solder drop passes through a series of dynamical shapes and finally assumes the spherical cap shape that is typically observed under equilibrium wetting conditions. No further spreading is observed at temperatures above $400^{\circ} \mathrm{C}$. At the end of the temperature ramp, the tin solder ball exhibited a wetted area of $9.3 \mathrm{~mm}^{2}$ corresponding to a solder contact angle of $31^{\circ}$ as calculated from the solder drop weight and the wetted area, assuming a spherical cap shape. The assumption of a spherical cap is valid, as long as capillary forces are stronger than other applied forces, such as gravity. As long as the radius of the area of spreading, $r$, is smaller than the capillary length, $\mathrm{K}^{-1}$, then capillary forces will dominate and spherical spreading should be observed. ${ }^{10}$ The capillary length is given by:

$$
\kappa^{-1}=\sqrt{\frac{\gamma}{\rho \bullet g}}
$$

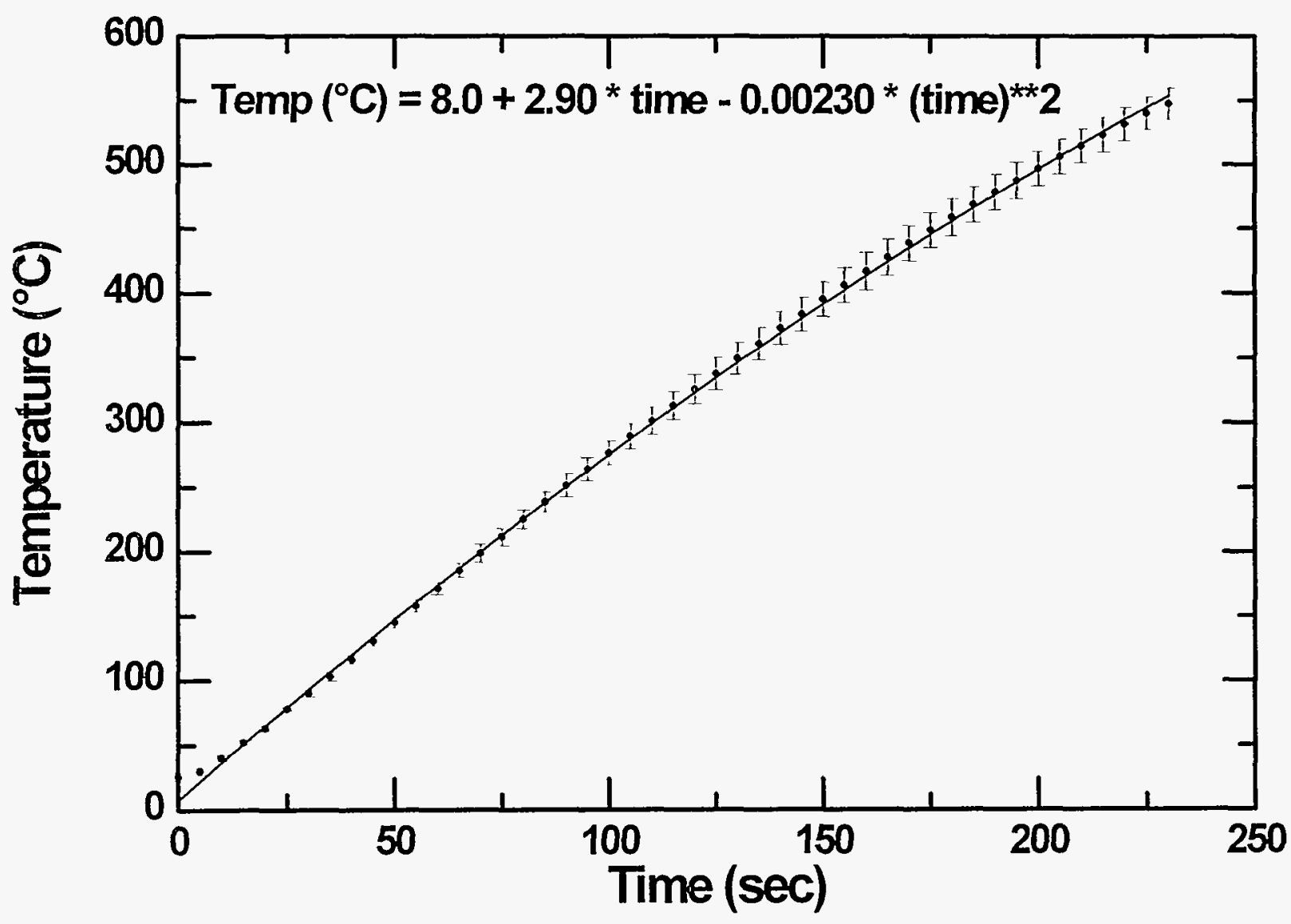

Figure 7: Temperature versus time function used for temperature estimates in temperature ramp spreading experiments where a thermocouple could not be used (solid line). The solid symbols show the average temperatures measured from four calibration temperature ramps at specific heating times after initiation of the ramp. The error bars represent the standard deviation in the average temperature measurements. 
where $\rho$ is the density of the liquid, $\gamma$ is the interfacial tension between the liquid and the gas, and $g$ is the gravitational acceleration. ${ }^{10}$ For tin: $\rho$ is about $10 \mathrm{~g} / \mathrm{cm}^{3}, \gamma$ is about $500 \mathrm{dyn}-\mathrm{cm} / \mathrm{cm}^{2}$ and $g$ is $980.6 \mathrm{~cm} / \mathrm{s}^{2}$, producing $\mathrm{K}^{-1}=2.2 \mathrm{~mm}$. Since $r=1.7 \mathrm{~mm}$ for the final wetted area, the assumption of a spherical cap is reasonably good.

The results of the temperature ramp spreading experiments for pure tin solder on the sputtercleaned, air-exposed and as-received copper surfaces are compared in Figure 9. The chemistry and oxide thickness on each of these copper surfaces is discussed in detail in section 3.5. Briefly, the airexposed copper surface is coated with a $\mathrm{Cu}_{2} \mathrm{O}$ film about $3 \mathrm{~nm}$ thick while the as-received surface is coated with a $\mathrm{Cu}_{2} \mathrm{O}$ film about $8 \mathrm{~nm}$ thick. The sputter-cleaned copper surface contains no significant amount of surface oxide. The observed melting temperature of the solder ball was $240 \pm 7^{\circ} \mathrm{C}$ for these three ramp experiments. Figure 9 clearly shows that the initiation temperature for solder spreading decreases with decreasing oxide thickness, from $325^{\circ} \mathrm{C}$ for the as-received copper surface

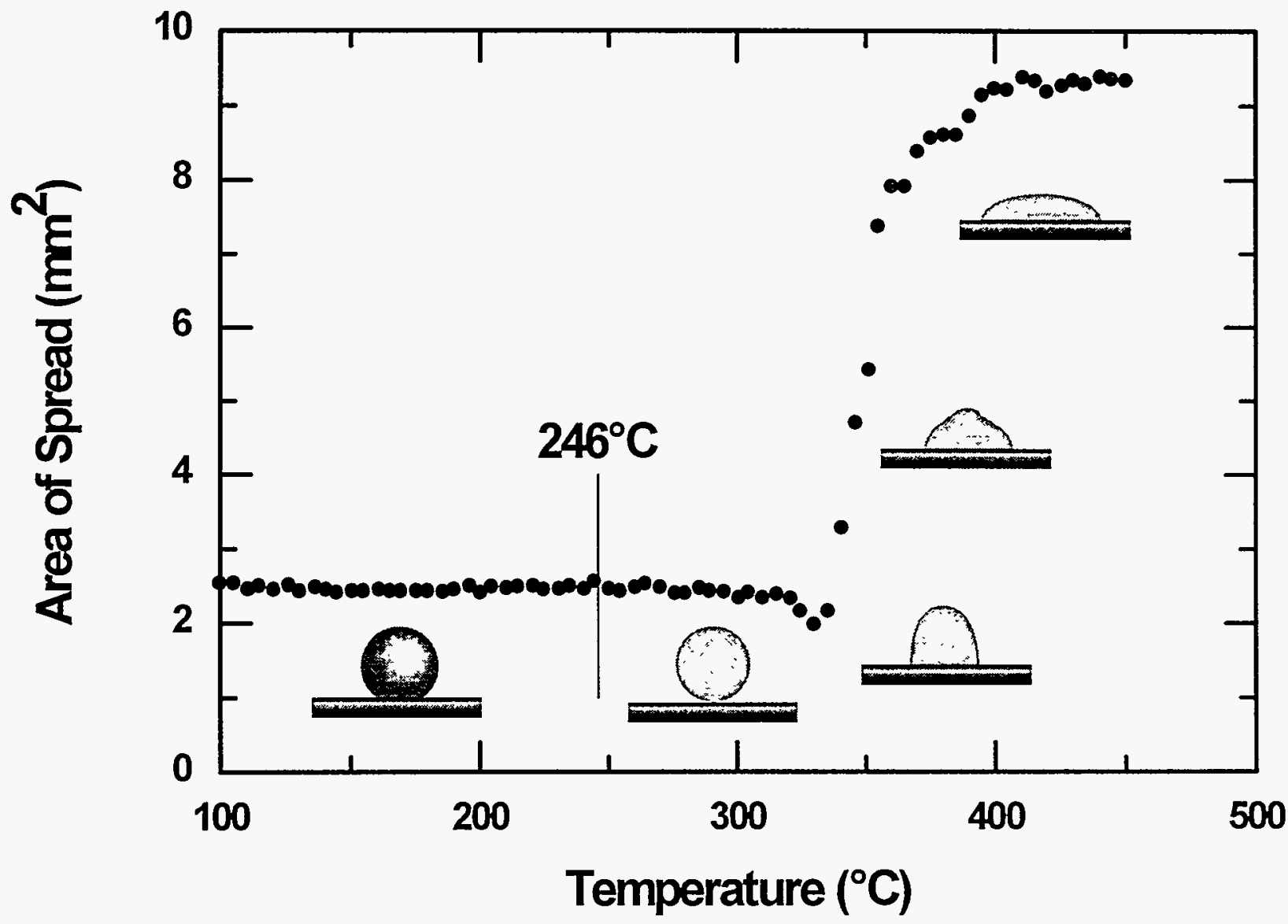

Figure 8: Spreading of pure tin solder on the as-received copper surface as a function of sample temperature during a temperature ramp experiment in 50 torr purified helium. The observed melting temperature of the tin solder ball is indicated by the vertical line in the graph. Superimposed on the graph are drawings of the shape of the solder drop at each stage of the spreading experiment. 
to $262^{\circ} \mathrm{C}$ for the air-exposed surface to $237^{\circ} \mathrm{C}$ for the sputter-cleaned surface. On the sputter-cleaned copper surface, spreading began as soon as the tin solder ball began to melt, but before the solder ball was completely liquefied. The initial rate of spreading was observed to increase with decreasing oxide thickness from $0.15 \mathrm{~mm}^{2} /{ }^{\circ} \mathrm{C}$ for the as-received copper surface, to $0.63 \mathrm{~mm}^{2} /{ }^{\circ} \mathrm{C}$ for the airexposed surface, to $2.4 \mathrm{~mm}^{2} /{ }^{\circ} \mathrm{C}$ for the sputter-cleaned surface. The spreading curve for the sputtercleaned surface is significantly different from the curves for the oxide-covered surfaces. On the oxide-covered surfaces, the spreading rate is initially fast and gradually slows, asymptotically approaching an equilibrium spread area. On the sputter-cleaned surface, however, the spreading rate is very fast, with an abrupt stop to spreading near the equilibrium spread area. This behavior is reproducible on the sputter-cleaned surface and has been obtained on several ramp experiments. This behavior suggests that the spreading process may be very different on the sputter-cleaned surface, relative to the oxide-covered surfaces.

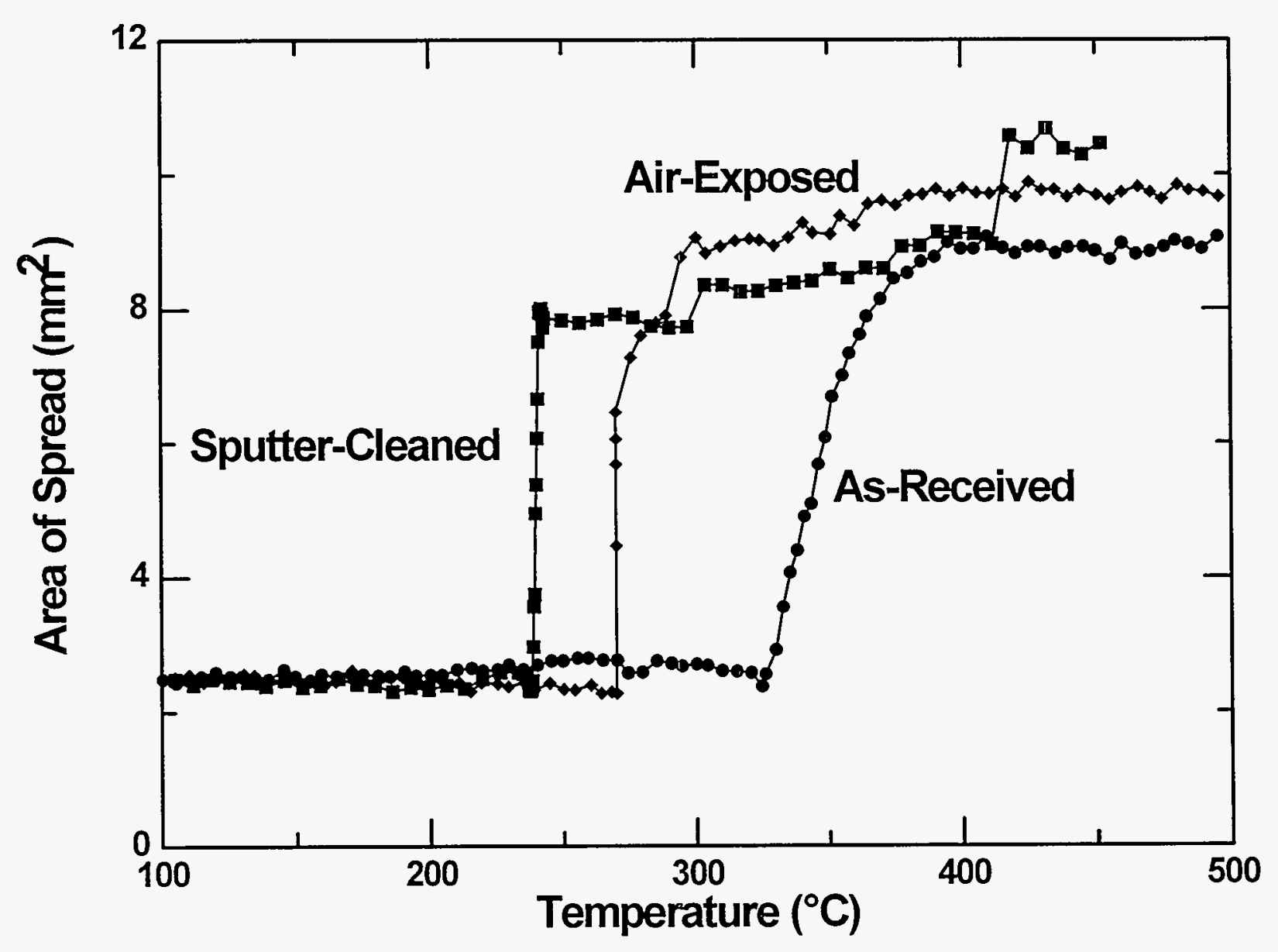

Figure 9: Results of temperature ramp experiments for the spreading of pure tin solder on three different copper substrates of varying surface oxide thicknesses. Oxide thickness are $3 \mathrm{~nm}$ for the air-exposed copper surface and $8 \mathrm{~nm}$ for the as-received surface. The sputter-cleaned copper surface contains no significant amount of surface oxide. 


\subsection{Isothermal Spreading Kinetics on the As-Received Copper Surface}

In order to measure accurate spreading kinetics for pure tin solder on copper as a function of oxide thickness, isothermal spreading experiments were performed. Results for the as-received copper surface will be presented in this report. Results for the sputter-cleaned copper surface and other oxide thicknesses on copper will be presented at a later date. Figure 10 shows the results obtained for the isothermal spreading of pure tin solder on the as-received copper surface at $280 \pm 1{ }^{\circ} \mathrm{C}$. The temperature uncertainty is the standard deviation of the temperature drift relative to the average value measured over the duration of the spreading experiment. The spreading parameter used in Figure 10 is area/circumference $(A / C)$. For a circular solder drop, $A / C$ is directly proportional to the radius of the solder drop $(r)$ as indicated by the equation:

$$
\frac{A}{C}=\frac{\pi \cdot r^{2}}{2 \cdot \pi \cdot r}=\frac{r}{2}
$$

where $A$ is the area of spread, $C$ is the solder drop circumference, $r$ is the radius, and $t$ is time. It then follows that the time derivative of $A / C$ is directly proportional to the linear rate of advancement of the wetting front, $d r / d t$, as indicated by the equation:

$$
\frac{d}{d t}\left(\frac{A}{C}\right)=\frac{d r}{2 \cdot d t}
$$

The solid symbols in Figure 10 show the data obtained from the top view camera, where both spreading area and circumference were measured directly from the video data. As noted previously, when the solder drop first begins to spread, a decrease is observed in both the area and circumference of the solder drop as the volume underneath the drop fills in. Following this initial decrease, $A / C$ increases rapidly with time in a linear fashion. The spreading rate then decreases in an exponential manner as the wetted area asymptotically approaches the value corresponding to the equilibrium shape of the solder drop on the substrate surface. The spreading rate of primary interest in this study is the initial linear spreading rate observed early in the spreading event. For the top view camera, the wetted area at very early times is obscured by the bulk of the solder drop as shown by the schematic diagram included in Figure 10. To alleviate this problem, the apparent length of the contact line between the solder and the substrate was measured from the side view video data, and this diameter was used to calculate the $A / C$ ratio, assuming a circular contact area. The results are shown as the open symbols in Figure 10. As can clearly be seen in the figure, good agreement was obtained between the $A / C$ ratios measured directly from the top view video data and the $A / C$ ratios calculated from the side view data. Since use of the side view data allowed measurement of the initial solder spreading rate at much earlier times in the spreading event than the top view data, $A / C$ ratios calculated from the side view video data were used exclusively to determine initial spreading rates for the isothermal spreading experiments reported in this section.

The initial rates of spreading were determined from the slope of the plot of $A / C$ versus time for each temperature, as determined from the side view video data. Figure 11 shows this plot for a run at $280.0 \pm 0.6^{\circ} \mathrm{C}$. As above, the uncertainty in temperature reflects the standard deviation of the temperature from the average during the actual time period used to determine the slope of the data. 
The solid line plotted in the figure represents a linear least-squares fit to the data. The oscillation of the data points about the line appears to be due to small temperature drifts with time as the temperature controller tries to keep the temperature constant. When the temperature rises by a small increment (usually $<1^{\circ} \mathrm{C}$ ), the tin solder spreads faster, giving a higher $A / C$ value than expected for a linear spreading rate. Conversely, when the temperature drops by a small increment, the tin solder spreads slower and the $A / C$ ratio is smaller than expected. This effect is much more pronounced at lower temperatures, where the spreading rate is very low. Figure 12 shows a selection of solder spreading experiments at various temperatures. It is obvious that the spreading rate increases rapidly with increases in temperature, indicating the solder spreading on the as-received copper surface is a thermally activated process.

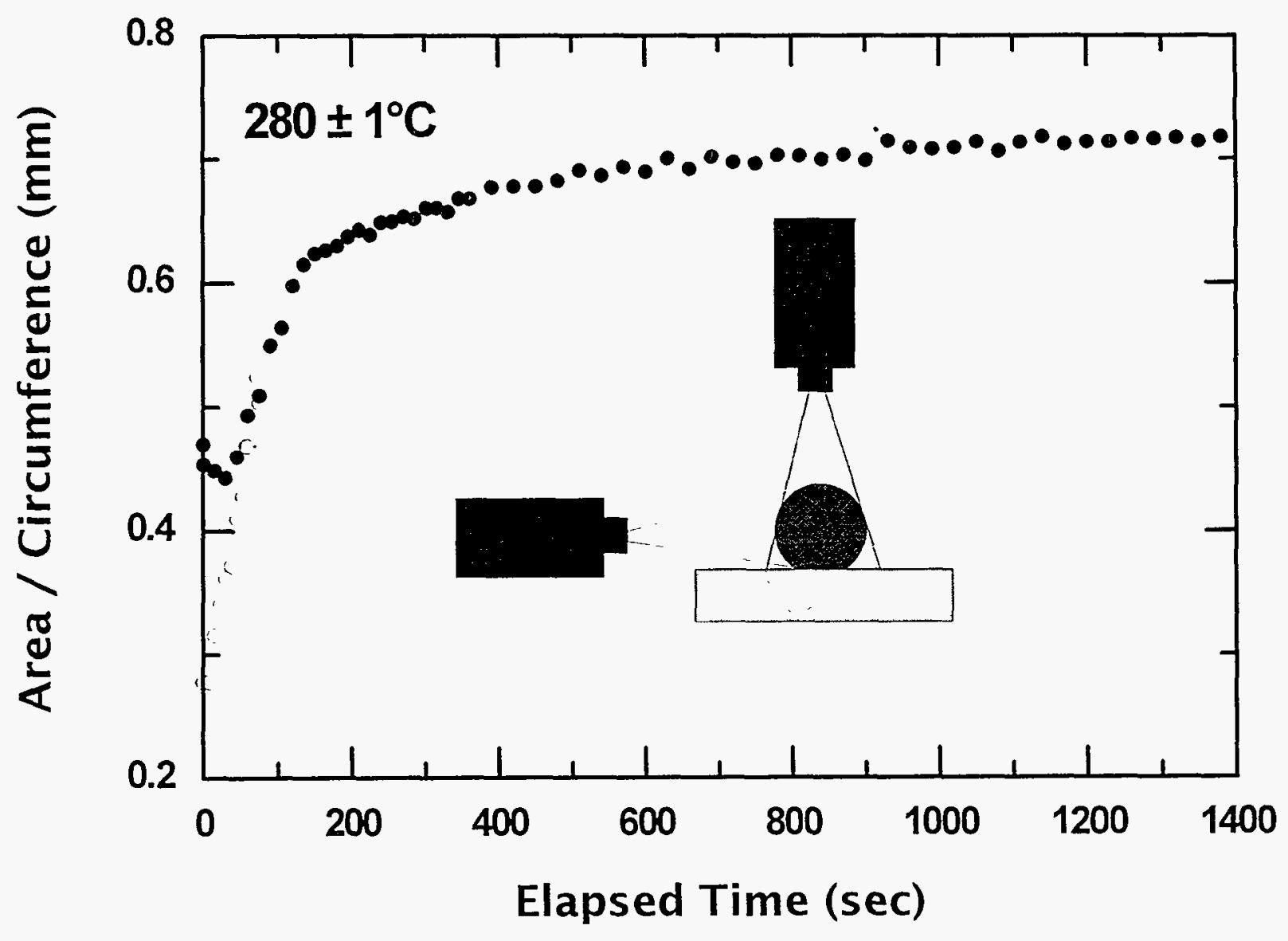

Figure 10: Isothermal spreading of pure tin solder on the as-received copper surface as a function of time, as determined from the top view (O) and side view (O) video cameras. Area and circumference are measured directly from the top view video image. From the side view video data, the A/C ratio is calculated from the length of the contact line (diameter) of the solder drop on the substrate surface. 
In order to determine the activation energy for the spreading of tin solder on as-received copper surfaces, the isothermal spreading rate data was plotted in an Arrhenius plot. The reaction rate was assumed to be of the form:

$$
\frac{d}{d t}\left(\frac{A}{C}\right)=\frac{d r}{2 \bullet d t}=\frac{k}{2} \bullet \exp \left(-\frac{E_{a}}{R \bullet T}\right)
$$

where $k$ is a constant if all other rate determining factors (such as chimical composition at the triplephase line) remain constant over the duration of the measurement, $E_{a}$ is the activation energy for the reaction, $T$ is the temperature in $\mathrm{K}$ and $R$ is the universal gas constant. Figure 13 shows the Arrhenius plot for isothermal spreading data from 262 to $331^{\circ} \mathrm{C}$. These temperatures represent the extremes readily available for study with our current experimental system. The lower temperature represents an initial linear spreading time of about 5 minutes (nearly 30 minutes to reach wetting equilibrium), while the higher temperature represents an initial linear spreading time $<1$ second, which requires

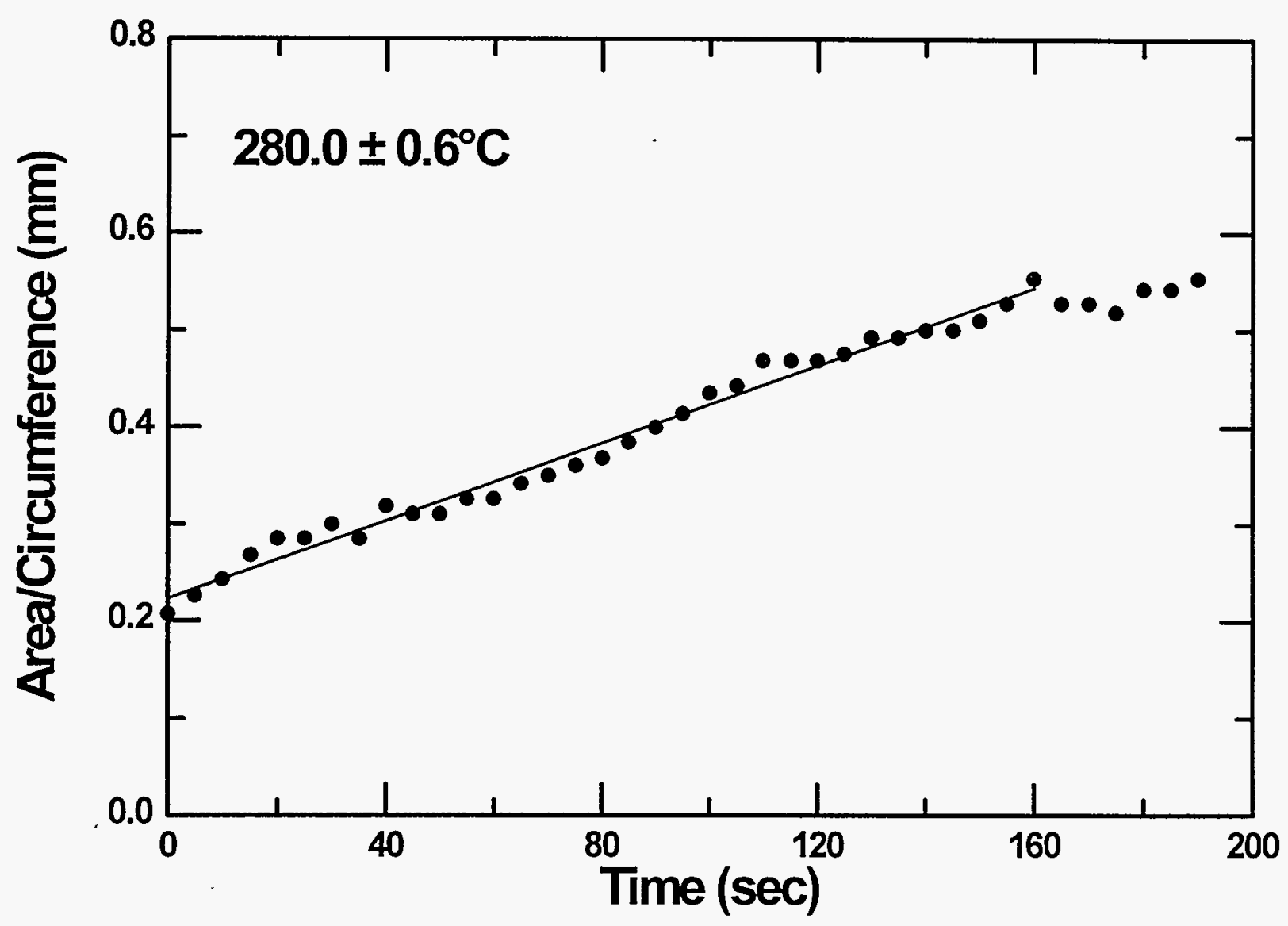

Figure 11: Isothermal spreading of pure tin solder on the as-received copper surface at $280.0 \pm 0.6^{\circ} \mathrm{C}$, as measured from the side view video data. The uncertainty in temperature reflects the standard deviation of the temperature from the average value during the actual time period used to determine the slope of the data. The solid line plotted in the figure is the leastsquares fit of the data. 
collecting data from every video frame to get an adequate sampling density for the spreading rate. The solid line shows the least-squares fitting of the data up to $327^{\circ} \mathrm{C}$, which yields an activation energy of $39.4 \mathrm{kcal} / \mathrm{mole}$, excluding the two data points at 330 and $331^{\circ} \mathrm{C}$. These two data points are much farther from the line than any of the other data, and are believed to represent a true change in activation energy or a discontinuity in the rate of spreading above $330^{\circ} \mathrm{C}$, due to a change in reaction mechanism or a change in surface state. The scatter of the points about the line are believed to be a result of non-uniformity of the air-passivated surfaces used for these experiments. The largest error in the $\mathrm{x}$-axis direction due to the drifting of temperature during a given isothermal run is only $0.5 \%$. The largest error in the y-axis direction due to the error in determining the slope of the area/circumference versus time plots is only $10 \%$, with typical values near $4 \%$. At these values, error bars showing a single standard deviation do not extend beyond the edges of the circular symbols used in the plot. The error in determining the activation energy is $3.1 \mathrm{kcal} / \mathrm{mole}$, as determined by the standard deviation of the least-squares fitting for the slope determination.

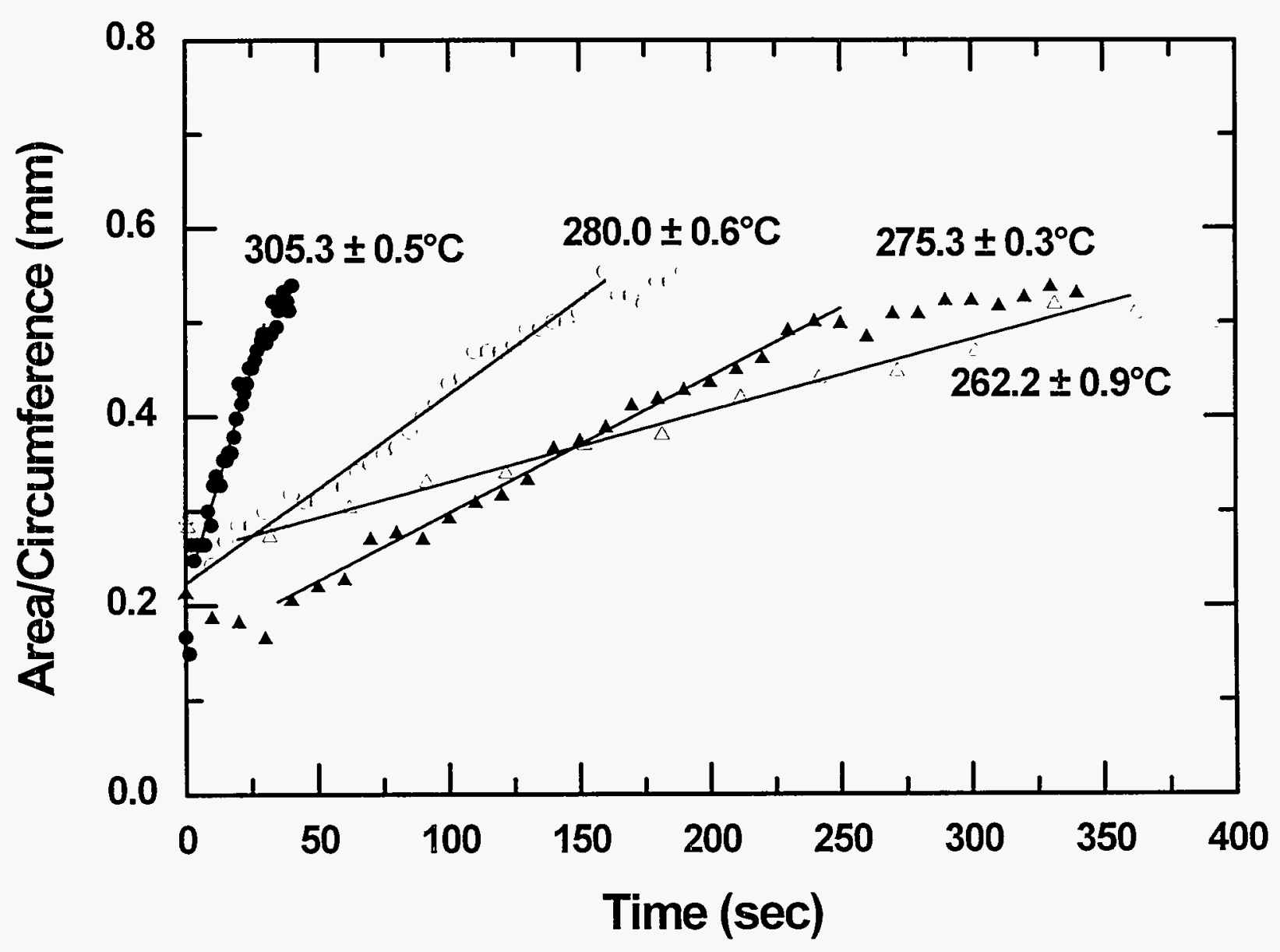

Figure 12: Isothermal spreading of pure tin solder on the as-received copper surface for selected substrate temperatures. The uncertainty in temperature reflects the standard deviation of the temperature from the average value during the actual time period used to determine the slope of the data. The solid lines plotted in the figure are the least-squares fits of the data. 


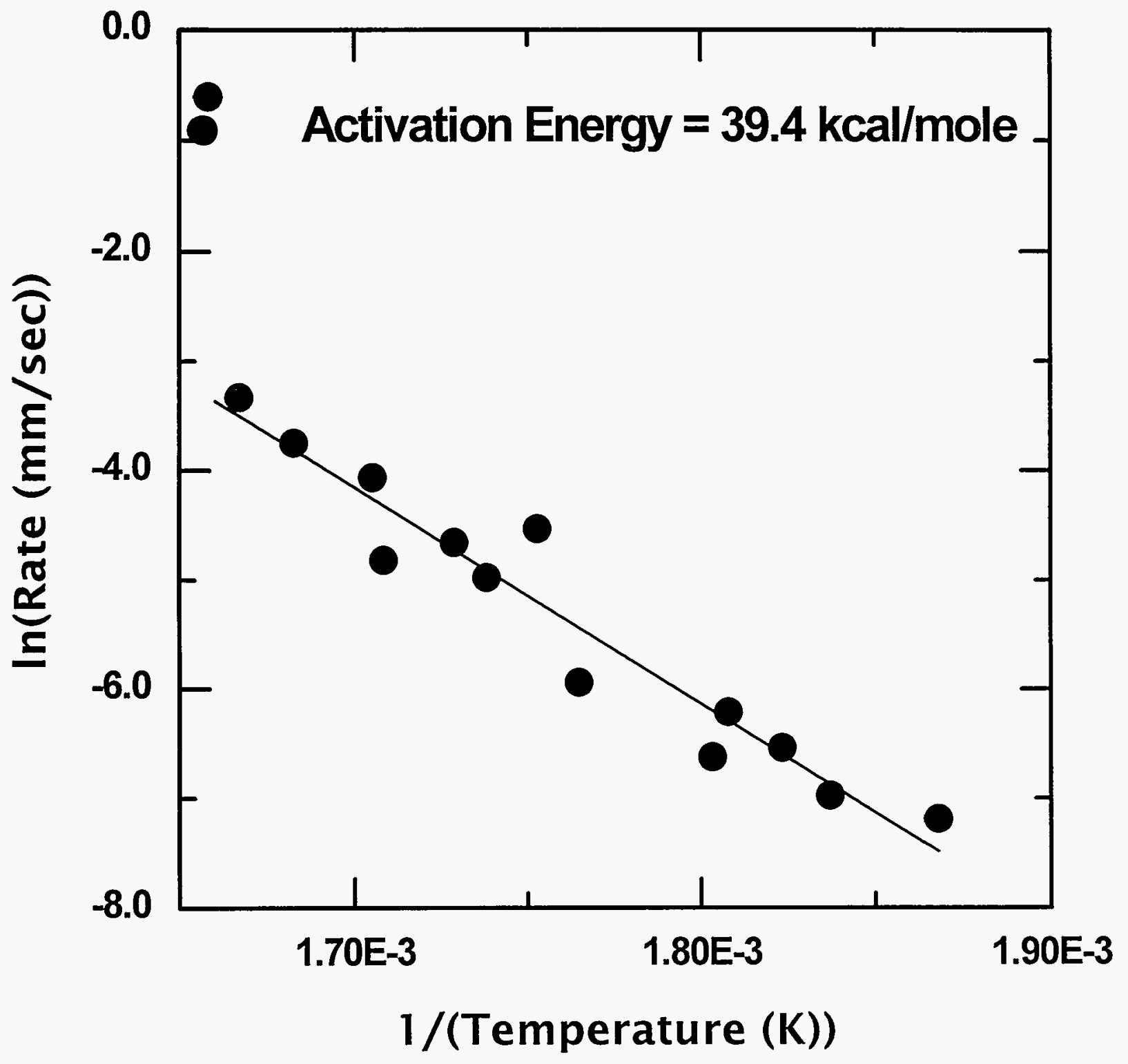

Figure 13: Arrhenius plot for the isothermal spreading of pure tin solder on the as-received copper surface in the temperature range from 262 to $331^{\circ} \mathrm{C}$. The solid line shows the leastsquares fitting of the data up to $327^{\circ} \mathrm{C}$, which yields an activation energy of $39.4 \pm 3.1 \mathrm{kcal} / \mathrm{mole}$, excluding the two data points at 330 and $331^{\circ} \mathrm{C}$. The spreading rate used in this figure is the slope of the A/C versus time plots obtained from the isothermal spreading experiments as a function of temperature.

Page 25 


\section{3. + Metallurgical Analysis}

In order to evaluate intermetallic formation during the spreading experiments, representative samples were cross-sectioned through the center of the tin solder drop after spreading was completed. These samples were sectioned, mounted, ground and polished to a $0.05 \mu \mathrm{m}$ finish. After polishing, the samples were etched by swabbing briefly with a solution of $40 \mathrm{ml} \mathrm{NH} \mathrm{NH}_{4} \mathrm{OH}$ and $2 \mathrm{ml} 30 \% \mathrm{H}_{2} \mathrm{O}_{2}$. This solution etches copper but not tin, showing the interfaces and grain boundaries as gray shadows. With this etch, the $\mathrm{Cu}_{6} \mathrm{Sn}_{5}$ intermetallic shows up as a light gray, while the $\mathrm{Cu}_{3} \mathrm{Sn}$ intermetallic shows up as a dark gray. Micrographs were then taken of the samples at $1000 \mathrm{X}$ to show the interfaces and intermetallics.

Micrographs are shown in Figure 14 for the samples run at the highest and lowest temperatures studied in the isothermal experiments. These micrographs show that there are no significant differences in the microstructure between the samples, verifying that the mechanism responsible for solder wetting on the as-received copper substrates produces the same final state throughout the temperature range studied. The micrographs show a thin layer of $\mathrm{Cu}_{3} \mathrm{Sn}$ along the interface of the copper and tin, extending out as a thin foot at the very edges of the tin drop. Between the $\mathrm{Cu}_{3} \mathrm{Sn}$ and the bulk of the tin drop, a much thicker, irregular layer of the $\mathrm{Cu}_{6} \mathrm{Sn}_{5}$ intermetallic is observed. This intermetallic also extends into the perimeter area of the drop. Both of these intermetallics occur unbroken throughout the entire tin-copper interfacial zone, indicating very good interaction between the tin and copper with no apparent inclusions or unwetted areas due to remaining copper oxide in the interfacial zone.

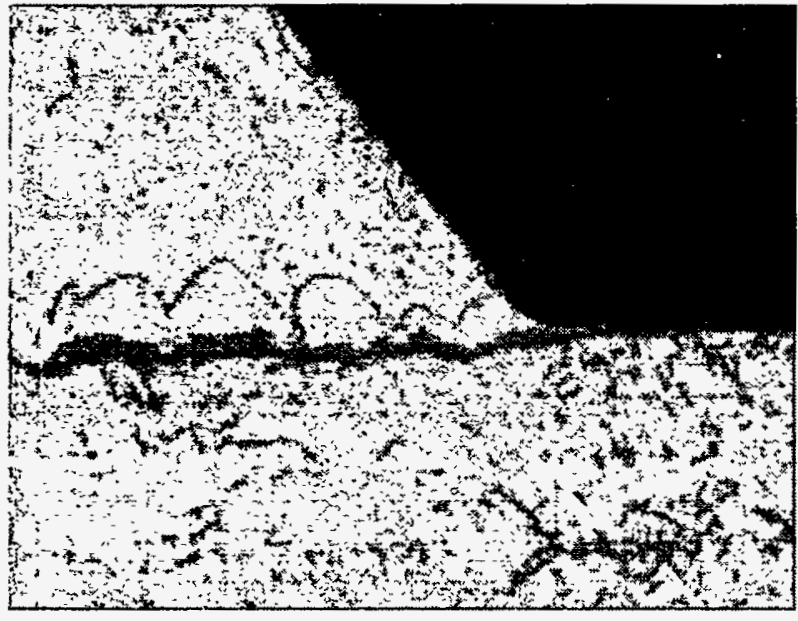

$262^{\circ} \mathrm{C}$

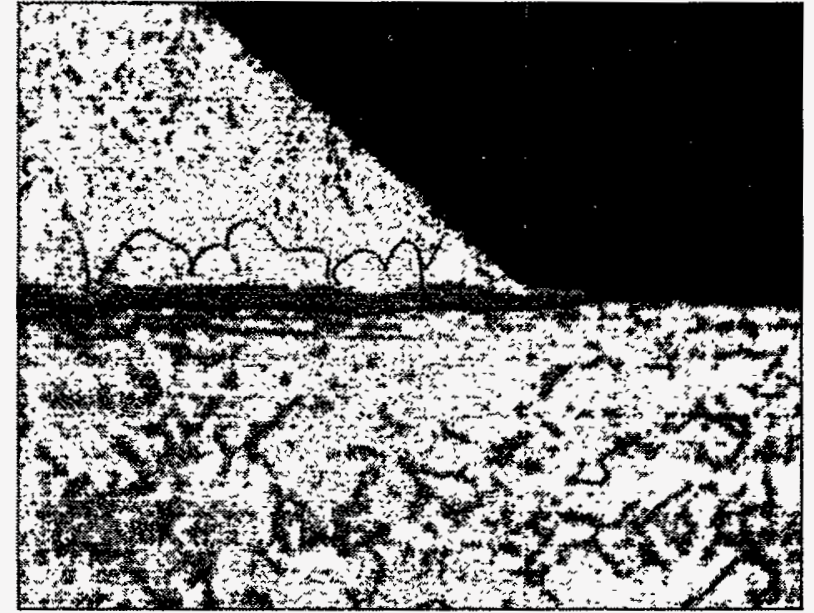

$330^{\circ} \mathrm{C}$

Figure 14: Optical micrographs of the edge of the tin-copper interface following the isothermal spreading of pure tin solder on the as-received copper substrate. The spreading temperature is noted under each micrograph. 


\subsection{Surface Chemistry}

Figures 15 through 17 show the non-angle-resolved $\mathrm{O} 1 \mathrm{~s}, \mathrm{Cu} 2 \mathrm{p}$ and $\mathrm{Cu}$ LMM x-ray photoelectron spectra for all surface conditions utilized in these experiments. The $C 1 \mathrm{~s}$ spectra (not shown) are all identical in peak shape for each surface examined (except for the peak shift on the sputter-cleaned surface), justifying the use of the $\mathrm{C} 1 \mathrm{~s}$ peak position for energy referencing. No stable carbide species are formed on copper; this peak is representative of adsorbed species, including miscellaneous hydrocarbons and carbon monoxide. Throughout this paper, we have used the nomenclature as-received surface for the air-passivated copper oxide surface used without any modification, except for the $300^{\circ} \mathrm{C}$ preheating for the isothermal spreading experiments. However, the actual as-received surface is quite unstable in vacuum, converting rather quickly to the vacuumreduced surface shown in Figures 15 through 17. In fact, the surface reduction occurs within the space of time required to record a normal set of scans, about 1 hour. Consequently, no angle-resolved spectra could be obtained for this surface, since the surface converts to the vacuum-reduced surface long before any angle-resolved spectra could be completed. Angle-resolved spectra were obtained for each of the other surface conditions to facilitate interpretation of the depth distribution of each chemical species. It should be noted that all surfaces referred to as "as-received" for spreading experiments are actually the vacuum-reduced surface (ramp experiments) or the surface heated to $300^{\circ} \mathrm{C}$ or $330^{\circ} \mathrm{C}$ (isothermal experiments).

The non-angle-resolved $O$ 1s spectra are shown in Figure 15. These spectra are displayed in relative intensity values, without normalization, in order to give the reader an indication of the changes in oxygen concentration on the surface. The unstable as-received surface (a) shows a large oxygen peak at a binding energy of $531.5 \mathrm{eV}$ and a peak width of about $2.6 \mathrm{eV}$. The stabilized vacuum-reduced surface (b) shows a much smaller peak at $530.9 \mathrm{eV}$, with a slightly increased width of $2.8 \mathrm{eV}$. After heating this surface to $300^{\circ} \mathrm{C}$ (c), the peak is about the same size and binding energy, $530.8 \mathrm{eV}$, but shows a much larger width of $3.5 \mathrm{eV}$. When the surface is heated to $330^{\circ} \mathrm{C}$ (d), the peak is reduced and shifts to $531.5 \mathrm{eV}$, but stays very broad, with a width of $4.0 \mathrm{eV}$. The sputtercleaned surface (f) shows only a trace of oxygen near $530 \mathrm{eV}$. When the sputter-cleaned surface is exposed to air for 5 minutes (e), a narrow peak $(2.4 \mathrm{eV})$ at $530.5 \mathrm{eV}$ is obtained, with a size similar to that observed for the vacuum-reduced surface. Previous studies report $\mathrm{O} 1 \mathrm{~s}$ binding energies of 529.5 to $529.6 \mathrm{eV}$ for $\mathrm{CuO},{ }^{11-13} 530.3$ to $530.6 \mathrm{eV}$ for $\mathrm{Cu}_{2} \mathrm{O},{ }^{11,13,14}$ and $531.1 \mathrm{eV}$ for $\mathrm{Cu}(\mathrm{OH})_{2}{ }^{13}$ In addition, binding energies of 531.2 to $531.7 \mathrm{eV}$ are reported for adsorbed $(\mathrm{OH})^{-}$and 532.4 to 532.6 for adsorbed $\mathrm{H}_{2} \mathrm{O} .{ }^{13,15}$ Based on these values, we assign the following peak energies for this study: $530.5 \mathrm{eV}$ for $\mathrm{Cu}_{2} \mathrm{O}, 530.0 \mathrm{eV}$ for $\mathrm{CuO}, 531.5$ for $\mathrm{Cu}(\mathrm{OH})_{2}$ and 533.5 for $\mathrm{H}_{2} \mathrm{O}(\mathrm{a})$. Table 1 summarizes the binding energies observed and estimated for all of the surface species believed to be present on these surfaces.

The angle-resolved $\mathrm{O} 1 \mathrm{~s}$ spectra show considerable variation with sample condition and depth of analysis. On the sputter-cleaned copper surface, oxygen occurs at $529.9 \mathrm{eV}$ for the bulk scan and $530.5 \mathrm{eV}$ for the surface scan, with a shoulder appearing near $533.5 \mathrm{eV}$ for the surface scan. On the air-exposed copper surface, oxygen occurs at $530.0 \mathrm{eV}$ for the bulk scan and $530.3 \mathrm{eV}$ for the surface scan, with only a slight shoulder appearing near $533.5 \mathrm{eV}$ for the surface scan. On the vacuumreduced copper surface, oxygen occurs at $530.5 \mathrm{eV}$ for the bulk scan and $531.5 \mathrm{eV}$ for the surface scan, with a large shoulder appearing near $533.5 \mathrm{eV}$ for the surface scan. On the air-passivated 
surface heated to $300^{\circ} \mathrm{C}$, oxygen occurs at $530.6 \mathrm{eV}$ for the bulk and surface scans, although the surface scan contains a much broader peak (2.5 versus $3.7 \mathrm{eV})$. On the air-passivated surface heated to $330^{\circ} \mathrm{C}$, oxygen occurs at $530.8 \mathrm{eV}$ for the bulk scan and $531.6 \mathrm{eV}$ for the surface scan, with only a small broadening for the surface scan $(3.6$ versus $4.0 \mathrm{eV}$ ). In every case, the oxygen peak is broadened as it is shifted to higher binding energy in the surface scans, indicating the presence of

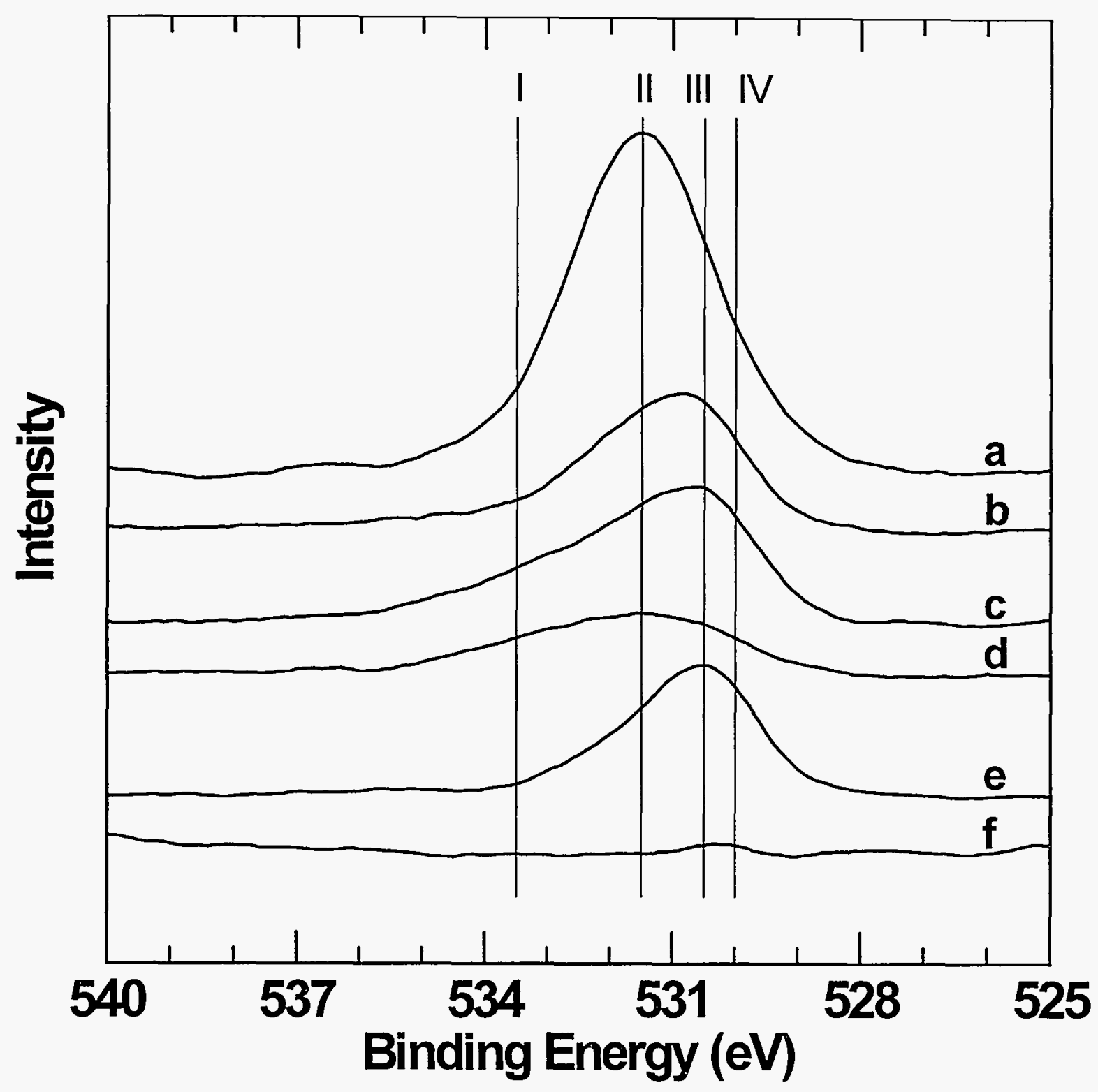

Figure 15: Representative non-angle-resolved $O$ Is $x$-ray photoelectron spectra for copper surfaces studied in this work. The surfaces are: (a) the unstable as-received surface; (b) the stabilized vacuum-reduced surface; (c) the as-received or vacuum-reduced surface heated to $300^{\circ} \mathrm{C}$; (d) the as-received or vacuum-reduced surface heated to $330^{\circ} \mathrm{C}$; (e) the sputtercleaned surface after a 5 minute air exposure; and $(f)$ the sputter-cleaned surface. The vertical lines show the binding energies expected for: (I) $\mathrm{H}_{2} \mathrm{O}$ at $533.5 \mathrm{eV}$; (II) $\mathrm{Cu}(\mathrm{OH})_{2}$ at $531.5 \mathrm{eV}$; (III) $\mathrm{Cu}_{2} \mathrm{O}$ at $530.5 \mathrm{eV}$; and (IV) $\mathrm{CuO}$ at $530.0 \mathrm{eV}$. 
additional species on the surface rather than a simple peak shift.

The non-angle-resolved $\mathrm{Cu} 2 \mathrm{p}_{3 / 2}$ spectra are shown in Figure 16. These spectra are displayed in normalized intensity, in order to give the reader a better indication of the changes in peak shape that occur. The unstable as-received surface (a) shows a very broad peak $(4.3 \mathrm{eV})$ at a binding energy of $933.5 \mathrm{eV}$ and shows the presence of large shake-up satellites in the 940 to $945 \mathrm{eV}$ range. The stabilized vacuum-reduced surface (b) shows a much narrower peak $(2.1 \mathrm{eV})$ at $932.6 \mathrm{eV}$, with no significant shake-up satellites. After heating this surface to $300^{\circ} \mathrm{C}(\mathrm{c})$ or $330^{\circ} \mathrm{C}(\mathrm{d})$, the peak is about the same size, width and binding energy, $932.4 \mathrm{eV}$. The sputter-cleaned surface (f) shows a narrow peak $(1.9 \mathrm{eV})$ at $92.2 \mathrm{eV}$ with no detectable shake-up satellite intensity. When the sputter-cleaned surface is exposed to air for 5 minutes (e), a narrow peak $(2.0 \mathrm{eV})$ at $932.4 \mathrm{eV}$ is. Previous studies report $\mathrm{Cu} 2 \mathrm{p}_{3 / 2}$ binding energies of 932.4 to $932.7 \mathrm{eV}$ for $\mathrm{Cu},{ }^{12-14,16,17} 932.0$ to $932.7 \mathrm{eV}$ (from 0.0 to about $0.2 \mathrm{eV}$ difference from $\mathrm{Cu}$ ) for $\mathrm{Cu}_{2} \mathrm{O},{ }^{11-14,17,18} 933.6$ to $933.8 \mathrm{eV}$ (from 1.0 to $1.3 \mathrm{eV}$ difference from $\mathrm{Cu})$ for $\mathrm{CuO},{ }^{11-13,17,18}$ and $935.0 \mathrm{eV}(2.5 \mathrm{eV}$ difference from $\mathrm{Cu})$ for $\mathrm{Cu}(\mathrm{OH})_{2} \cdot{ }^{13}$ Strong shakeup satellites are observed in all cases for $\mathrm{Cu}^{2+}$ species $\left(\mathrm{CuO}\right.$ and $\left.\mathrm{Cu}(\mathrm{OH})_{2}\right)$, but not for $\mathrm{Cu}^{0}$ and $\mathrm{Cu}^{1+}$ species ( $\mathrm{Cu}$ and $\mathrm{Cu}_{2} \mathrm{O}$, respectively). ${ }^{11-13,17,18}$ The shape of the satellite structure can be used to distinguish $\mathrm{CuO}$ from $\mathrm{Cu}(\mathrm{OH})_{2}$ : for $\mathrm{CuO}$ the satellite closest to the main $\mathrm{Cu} 2 \mathrm{p}_{3 / 2}$ peak is slightly stronger while for $\mathrm{Cu}(\mathrm{OH})_{2}$ the satellite farthest from the main peak is slightly stronger. ${ }^{13}$ Based on these values, we assign the following peak energies for this study: $932.2 \mathrm{eV}$ for $\mathrm{Cu} ; 932.4 \mathrm{eV}$ for $\mathrm{Cu}_{2} \mathrm{O}, 933.5 \mathrm{eV}$ for $\mathrm{CuO}$ and $\mathrm{Cu}(\mathrm{OH})_{2}$. The values for $\mathrm{CuO}$ is estimated relative to the $\mathrm{Cu}$ value, but was not observed in the spectra. Table 1 summarizes the binding energies observed and estimated for all of the surface species believed to be present on these surfaces.

Table 1: XPS Binding Energies (eV) for Surface Chemical Species

\begin{tabular}{|c|cccc|}
\hline Species & O 1s & Cu 3s & Cu 2p & Cu LMM \\
\hline $\mathrm{Cu}$ & - & 122.2 & 932.2 & 567.7 \\
$\mathrm{Cu}_{2} \mathrm{O}$ & 530.5 & 122.4 & 932.4 & 569.7 \\
$\mathrm{CuO}$ & 530.0 & $123.2^{*}$ & $933.5^{*}$ & $568.3^{*}$ \\
$\mathrm{Cu}(\mathrm{OH})_{2}$ & 531.5 & 123.2 & 933.5 & 570.2 \\
$\mathrm{H}_{2} \mathrm{O}(\mathrm{a})$ & 533.5 & - & - & - \\
\hline
\end{tabular}

*Species energy estimated relative to other species, but not actually observed.

Page 29 
The angle-resolved $\mathrm{Cu} 2 \mathrm{p}_{3 / 2}$ spectra show little variation with sample condition and depth of analysis. On the sputter-cleaned copper surface, the $\mathrm{Cu} 2 \mathrm{p}_{3 / 2}$ peak occurs at $932.2 \mathrm{eV}$ for the bulk and surface scans. On the air-exposed copper surface, the copper peak occurs at $932.4 \mathrm{eV}$ for the bulk

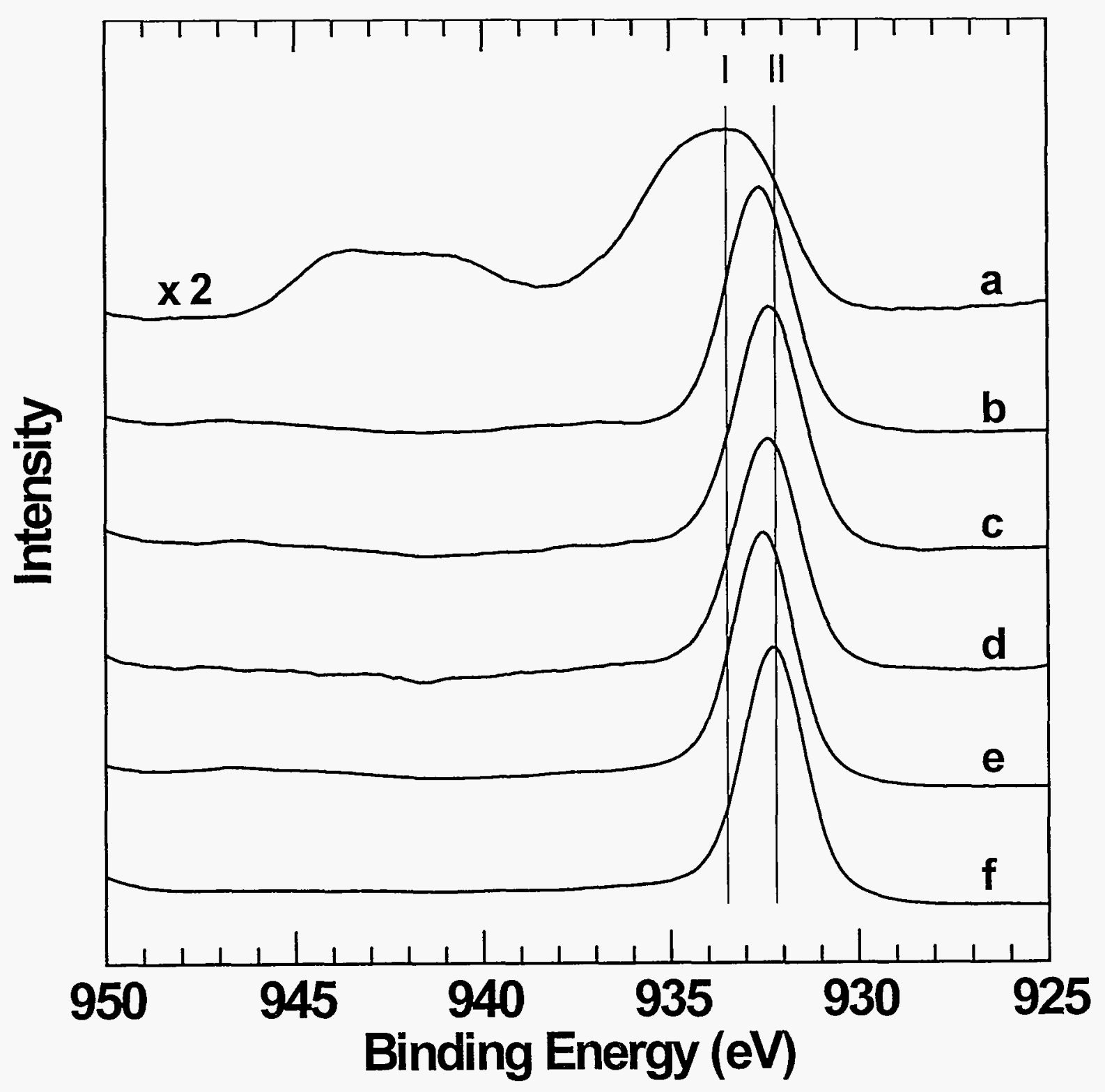

Figure 16: Representative normalized non-angle-resolved $\mathrm{Cu} 2 p_{3 / 2} x$-ray photoelectron spectra for copper surfaces studied in this work. The surfaces are: (a) the unstable asreceived surface; (b) the stabilized vacuum-reduced surface; (c) the as-received or vacuumreduced surface heated to $300^{\circ} \mathrm{C} ;(d)$ the as-received or vacuum-reduced surface heated to $330^{\circ} \mathrm{C}$; (e) the sputter-cleaned surface after a 5 minute air exposure; and (f) the sputtercleaned surface. The vertical lines show the binding energies expected for: (I) $\mathrm{CuO}$ and $\mathrm{Cu}(\mathrm{OH})_{2}$ at $933.5 \mathrm{eV}$; and (II) $\mathrm{Cu}$ at $932.2 \mathrm{eV}$. To avoid clutter in the graph, the line for $\mathrm{CuO}_{2}$ at $932.4 \mathrm{eV}$ is not shown. 
and surface scans, while on the vacuum-reduced copper surface, the copper peak occurs at $932.6 \mathrm{eV}$ for the bulk and surface scans. On the air-passivated surface heated to $300^{\circ} \mathrm{C}$, the copper peak occurs at $932.4 \mathrm{eV}$ for the bulk scan and at $932.3 \mathrm{eV}$ for the surface scan. On the air-passivated surface heated to $330^{\circ} \mathrm{C}$, the copper peak occurs at $932.4 \mathrm{eV}$ for the bulk and surface scans. In every case, the copper peak remains a very narrow, with no apparent broadening as a function of changing surface conditions or depth of analysis, indicating that multiple copper species do not exist in large amounts on the surface.

The non-angle-resolved $\mathrm{Cu}$ LMM spectra are shown in Figure 17. These spectra are displayed in normalized intensity, in order to give the reader a better indication of the changes in peak shape that occur. The unstable as-received surface (a) shows a very broad peak $(6.6 \mathrm{eV})$ at a binding energy of $570.2 \mathrm{eV}$. The stabilized vacuum-reduced surface (b) shows a much narrower peak (5.1 $\mathrm{eV}$ ) at $570.4 \mathrm{eV}$. After heating this surface to $300^{\circ} \mathrm{C}(\mathrm{c})$, the peak is essentially unchanged, while heating the surface to $330^{\circ} \mathrm{C}$ (d) shifts the main peak to $568.0 \mathrm{eV}$, with significant intensity remaining in the $570 \mathrm{eV}$ region. The sputter-cleaned surface (f) shows a very narrow peak $(2.6 \mathrm{eV})$ at $567.7 \mathrm{eV}$. When the sputter-cleaned surface is exposed to air for 5 minutes (e), a peak structure similar to that obtained by heating the air-passivated surface to $330^{\circ} \mathrm{C}$ is seen, with peak intensity almost equally distributed between 570 and $568 \mathrm{eV}$. The lineshape exhibited on the sputter-cleaned surface is typical of metallic copper, while the lineshape exhibited on the vacuum-reduced sample and on the sample heated to $300^{\circ} \mathrm{C}$ is typical of $\mathrm{Cu}_{2} \mathrm{O} .^{11-13,15,17,18}$ The sample heated to $330^{\circ} \mathrm{C}$ and the airexposed surface exhibit a mixture of these two lineshapes, with varying relative proportions of each contribution. The lineshape for $\mathrm{CuO}$ differs from each of these in shape and position. Previous studies have reported binding energies of 567.6 to $568.3 \mathrm{eV}$ for $\mathrm{Cu},{ }^{12,13,15-17} 569.5$ to $570.2 \mathrm{eV}$ (a difference of 1.9 to $2.3 \mathrm{eV}$ from $\mathrm{Cu}$ ) for $\mathrm{Cu}_{2} \mathrm{O},{ }^{11-13,15,17,18} 568.4$ to $568.9 \mathrm{eV}$ (a difference of 0.6 to 1.0 $\mathrm{eV}$ from $\mathrm{Cu}$ ) for $\mathrm{CuO},{ }^{11-13,15,17}$ and $570.3 \mathrm{eV}$ (a difference of $2.7 \mathrm{eV}$ from $\mathrm{Cu}$ ) for $\mathrm{Cu}(\mathrm{OH})_{2}{ }^{11}$ Based on these values, the following peak energies are assigned for this study: $567.7 \mathrm{eV}$ for $\mathrm{Cu}, 569.7 \mathrm{eV}$ for $\mathrm{Cu}_{2} \mathrm{O}, 568.3 \mathrm{eV}$ for $\mathrm{CuO}$ and 570.2 for $\mathrm{Cu}(\mathrm{OH})_{2}$. The value for $\mathrm{CuO}$ is estimated relative to the $\mathrm{Cu}$ value, but was not observed in the spectra. Table 1 summarizes the binding energies observed and estimated for all of the surface species believed to be present.

The angle-resolved $\mathrm{Cu}$ LMM spectra show considerable variation with sample condition and depth of analysis. On the sputter-cleaned surface, copper occurs at $567.7 \mathrm{eV}$ for the bulk and surface scans. On the air-exposed surface, copper occurs at $568.0 \mathrm{eV}$ for the bulk scan and $569.7 \mathrm{eV}$ for the surface scan. On the vacuum-reduced surface, copper occurs at $570.4 \mathrm{eV}$ for the bulk and surface scans. The air-exposed surface exhibits a mixture of the lineshapes of metallic copper and $\mathrm{Cu}_{2} \mathrm{O}$, with the relative proportions of each contribution varying between the bulk and surface scans. On the air-passivated surface heated to $300^{\circ} \mathrm{C}$, the peak occurs at $569.9 \mathrm{eV}$ for the bulk and surface scans. Although each spectra contains contributions from the lineshapes of metallic copper and $\mathrm{Cu}_{2} \mathrm{O}$, the lineshape of $\mathrm{Cu}_{2} \mathrm{O}$ predominates for both spectra. On the air-passivated surface heated to $330^{\circ} \mathrm{C}$, the peak occurs at $567.9 \mathrm{eV}$ for the bulk scan and 569.1 for the surface scan. A mixture of lineshapes occurs for both surfaces, but the surface scan contains roughly equal contributions of the lineshapes of metallic copper and $\mathrm{Cu}_{2} \mathrm{O}$, while the bulk scan contains primarily the lineshape of metallic copper. 
The non-angle-resolved $\mathrm{Cu} 3 \mathrm{~s}$ spectra (not shown) show the same basic information as the $\mathrm{Cu} 2 \mathrm{p}_{3 / 2}$ region. The unstable as-received surface shows a very broad peak $(5.0 \mathrm{eV})$ at a binding energy of $123.1 \mathrm{eV}$. The stabilized vacuum-reduced surface and the surface heated to $300^{\circ} \mathrm{C}$ show a much narrower peak $(3.1 \mathrm{eV})$ at $122.5 \mathrm{eV}$. After heating this surface to $330^{\circ} \mathrm{C}$, the peak is about the

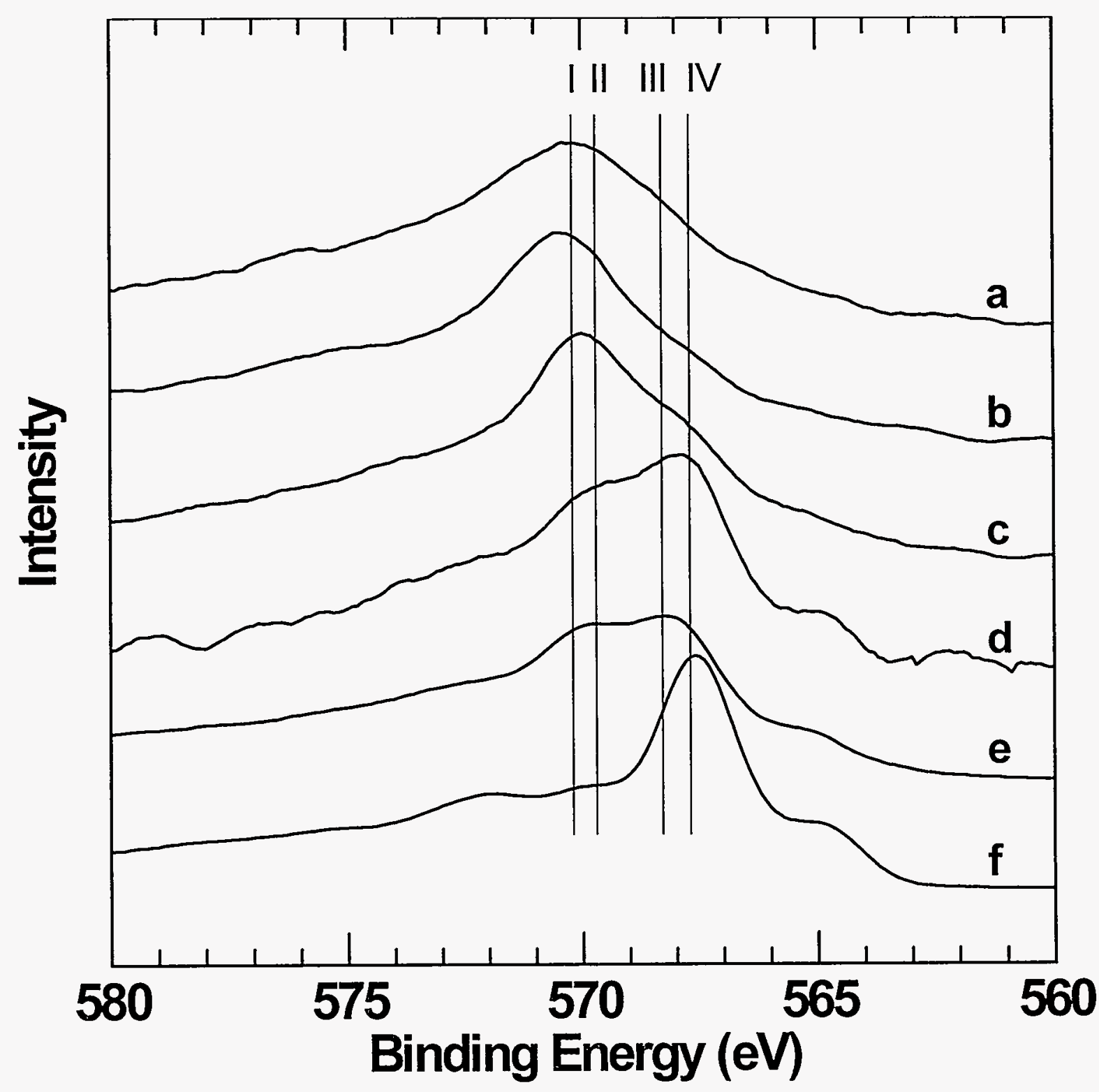

Figure 17: Representative normalized non-angle-resolved Cu LMM $x$-ray photoelectron spectra for copper surfaces studied in this work. The surfaces are: (a) the unstable asreceived surface; (b) the stabilized vacuum-reduced surface; (c) the as-received or vacuumreduced surface heated to $300^{\circ} \mathrm{C}$; (d) the as-received or vacuum-reduced surface heated to $330^{\circ} \mathrm{C}$; (e) the sputter-cleaned surface after a 5 minute air exposure; and $(f)$ the sputtercleaned surface. The vertical lines show the binding energies expected for: (I) $\mathrm{Cu}(\mathrm{OH})_{2}$ at $570.2 \mathrm{eV}$; (II) $\mathrm{Cu}_{2} \mathrm{O}$ at $569.7 \mathrm{eV}$; (III) $\mathrm{CuO}$ at $568.3 \mathrm{eV}$; and (IV) $\mathrm{Cu}$ at $567.7 \mathrm{eV}$. 
same width but shifts in binding energy to $122.2 \mathrm{eV}$. The sputter-cleaned surface shows a narrow peak $(3.0 \mathrm{eV})$ at 122.2 . When the sputter-cleaned surface is exposed to air for 5 minutes, the peak broadens slightly $(3.4 \mathrm{eV})$ while shifting to a slightly higher binding energy $(122.5 \mathrm{eV})$. Previous studies show a binding energy of 122.4 to $122.5 \mathrm{eV}$ for $\mathrm{Cu}^{14,16}$ and $122.5 \mathrm{eV}$ (a difference of $0.0 \mathrm{eV}$ relative to $\mathrm{Cu}$ ) for $\mathrm{Cu}_{2} \mathrm{O}{ }^{14}$ Based on these values, we assign the following peak energies for this study: $122.2 \mathrm{eV}$ for $\mathrm{Cu} ; 122.4 \mathrm{eV}$ for $\mathrm{Cu}_{2} \mathrm{O}, 123.2 \mathrm{eV}$ for $\mathrm{CuO}$ and $\mathrm{Cu}(\mathrm{OH})_{2}$. The value for $\mathrm{CuO}$ is estimated relative to the $\mathrm{Cu}$ value, but was not observed in the spectra. Table 1 summarizes the binding energies observed and estimated for all of the surface species believed to be present on these surfaces.

The angle-resolved $\mathrm{Cu} 3 \mathrm{~s}$ spectra show little variation with sample condition and depth of analysis. On the air-exposed surface, copper occurs at $122.2 \mathrm{eV}$ for the bulk scan and $122.4 \mathrm{eV}$ for the surface scan. On the vacuum-reduced surface, the copper peak occurs at $122.5 \mathrm{eV}$ for the bulk and surface scans. The sputter-cleaned surface shows copper at $122.3 \mathrm{eV}$ for the bulk and surface scans. On the air-passivated surface heated to both $300^{\circ} \mathrm{C}$ and $330^{\circ} \mathrm{C}$, the copper peak is at $122.3 \mathrm{eV}$ for the bulk scan and $121.9 \mathrm{eV}$ for the surface scan.

The results from these spectral regions are taken into account, from all spectral scans, in order to interpret the data to get a consistent picture of the surface chemistry for each condition. The asreceived sample is covered with a fairly thick layer of $\mathrm{Cu}(\mathrm{OH})_{2}$, although other species may be present as well. This layer is unstable, and is rapidly reduced under vacuum or heating conditions. Much of the oxygen is removed from the surface, probably by reaction and desorption as $\mathrm{H}_{2} \mathrm{O}$. The remaining oxygen is retained as $\mathrm{Cu}_{2} \mathrm{O}$. After vacuum reduction is complete, the sample is primarily $\mathrm{Cu}_{2} \mathrm{O}$ in the bulk, with some small contributions from $\mathrm{Cu}^{2+}\left(\mathrm{CuO}\right.$ and/or $\left.\mathrm{Cu}(\mathrm{OH})_{2}\right)$ and $\mathrm{Cu}$ species, while the surface remains primarily $\mathrm{Cu}(\mathrm{OH})_{2}$ with some contributions from $\mathrm{Cu}_{2} \mathrm{O}$ and $\mathrm{H}_{2} \mathrm{O}(\mathrm{a})$. The air-exposed sample is primarily $\mathrm{Cu}$ in the bulk and $\mathrm{Cu}_{2} \mathrm{O}$ on the surface, but some $\mathrm{CuO}$ is present in the bulk and some $\mathrm{Cu}(\mathrm{OH})_{2}$ is present on the surface. The sputter-cleaned sample shows primarily $\mathrm{Cu}$ in the bulk with small amounts of $\mathrm{CuO}$, and primarily $\mathrm{Cu}$ on the surface with small amounts of $\mathrm{Cu}_{2} \mathrm{O}, \mathrm{Cu}(\mathrm{OH})_{2}$, and $\mathrm{H}_{2} \mathrm{O}(\mathrm{a})$.

Heating the as-received or vacuum-reduced surface produces further changes in the surface chemistry. Heating to $300^{\circ} \mathrm{C}$ changes the surface significantly by removing more oxygen from the surface and converting any remaining $\mathrm{Cu}^{2+}$ species $\left(\mathrm{CuO}\right.$ and $\left.\mathrm{Cu}(\mathrm{OH})_{2}\right)$ present into $\mathrm{Cu}^{1+}$ species $\left(\mathrm{Cu}_{2} \mathrm{O}\right)$. Previous studies suggest that the $\mathrm{CuO}$ phase transforms to $\mathrm{Cu}_{2} \mathrm{O}$ at temperatures above $300^{\circ} \mathrm{C}$ in oxygen deficient atmospheres. ${ }^{19,20}$ Our results show complete conversion of $\mathrm{CuO}$ and $\mathrm{Cu}(\mathrm{OH})_{2}$ to $\mathrm{Cu}_{2} \mathrm{O}$ with only brief heating at $300^{\circ} \mathrm{C}$ in 50 torr helium, verifying the purity of the helium ambient, since the oxygen pressure-temperature phase diagram for the copper system is very sensitive to the oxygen pressure at these low temperatures. ${ }^{19}$ Because of the conversion of $\mathrm{Cu}^{2+}$ species to $\mathrm{Cu}^{1+}$ species upon heating, the isothermal spreading experiments were conducted on surfaces with fairly uniform composition, in spite of the wide variations observed in the as-received samples. Further heating to $330^{\circ} \mathrm{C}$ makes rather dramatic changes in the surface chemistry. The amount of oxygen remaining on the surface is considerably reduced, probably by diffusion into the bulk, although reaction and desorption can not be completely ruled out. The surface also shows a considerable shift from $\mathrm{Cu}_{2} \mathrm{O}$ species to $\mathrm{Cu}$, especially in the bulk, suggesting that the remaining $\mathrm{Cu}_{2} \mathrm{O}$ layer is much thinner after heating to $330^{\circ} \mathrm{C}$ than it is after heating to $300^{\circ} \mathrm{C}$. In fact, while 
heating the surface to $300^{\circ} \mathrm{C}$ appears to leave the $\mathrm{Cu}_{2} \mathrm{O}$ layer about as thick as that observed for the vacuum-reduced sample, after heating to $330^{\circ} \mathrm{C}$ the $\mathrm{Cu}_{2} \mathrm{O}$ layer appears to have about the same thickness as that obtained by a 5 minute air exposure of the sputter-cleaned copper surface.

Sampling depths have been calculated for each peak and scan condition, based on estimated values for the electron mean free paths. Using the method of Seah and Dench, ${ }^{21}$ the electron mean free path is given by:

$$
\lambda_{n}=a \cdot \lambda_{m}
$$

where: $\lambda_{n}$ is the electron mean free path in $\mathrm{nm}, \lambda_{m}$ is the electron mean free path in monolayers and $a$ is the monolayer thickness in $\mathrm{nm}$. The value for $a$ is given by:

$$
a^{3}=\frac{W}{\rho \bullet n \bullet N} \cdot 10^{24}
$$

where $W$ is the atomic or molecular weight, $n$ is the number of atoms in the molecule, $N$ is Avogadro's number and $\rho$ is the bulk density in $\mathrm{kg} / \mathrm{m}^{3}$. For inorganic compounds, the electron mean free path is then given by:

$$
\lambda_{m}=\frac{2170}{E^{2}}+0.72 \cdot \sqrt{a \bullet E}
$$

where $E$ is the electron kinetic energy in $\mathrm{eV}$. Since the surfaces observed here primarily consisted of $\mathrm{Cu}_{2} \mathrm{O}$, the values of $\mathrm{Cu}_{2} \mathrm{O}$ were used to calculate the monolayer thickness, $a$. Using $W=143.08 \mathrm{~g}$, $n=3, \rho=6,000 \mathrm{~kg} / \mathrm{m}^{3}$ for $\mathrm{Cu}_{2} \mathrm{O}$ provides a value of $a=0.273 \mathrm{~nm}$. Table 2 lists the sampling depth, $d$, for each peak energy and scan angle studied, assuming that the sampling depth is given by:

$$
d=3 \bullet \lambda_{n} \bullet \cos (\theta)
$$

where $\theta$ is the average detection angle relative to the sample surface normal.

Comparison of the data for each of the regions examined, in consideration of the sampling depth for each region and scan condition leads us to a general understanding of the chemical composition of each sample surface condition. Figure 18 illustrates schematically the species observed for each sample as a function of sampling depth. The drawings on the left show the species observed for each XPS region. The species listed on top for each block is the predominant species. Additional species observed are separated by commas while species that are of uncertain assignment are separated by "or". The sampling depths for each peak are shown as the height of the block for the surface and bulk scans. This data leads us to the conclusion that the vacuum reduced surface (labeled as-received) consists of about $8.0 \mathrm{~nm}$ of $\mathrm{Cu}_{2} \mathrm{O}$ on top of $\mathrm{Cu}$, capped off by about a monolayer $(0.3$ $\mathrm{nm}$ ) of $\mathrm{Cu}(\mathrm{OH})_{2}$. The air-exposed surface consists of about $3.0 \mathrm{~nm}$ of $\mathrm{Cu}_{2} \mathrm{O}$ on top of $\mathrm{Cu}$, with small amounts of $\mathrm{Cu}(\mathrm{OH})_{2}$ present in the outer monolayer. The sputter-cleaned sample consists of clean $\mathrm{Cu}$, with small amounts of $\mathrm{Cu}_{2} \mathrm{O}$ present in the outer monolayer. All samples have some $\mathrm{H}_{2} \mathrm{O}$ (a) on the outermost monolayer, while the air-exposed and sputter-cleaned samples have small amounts of 
lattice oxygen $(\mathrm{CuO})$ present in the near-surface region. The drawings on the right in Figure 18 show the interpretation of this data into the actual surface structures versus depth proposed for each sample condition. Previous studies show that oxidation of copper at low temperatures proceeds by oxygen adsorption and lattice incorporation followed by the growth of $\mathrm{Cu}_{2} \mathrm{O} .{ }^{22,23}$ Only at higher temperatures and pressures is significant $\mathrm{CuO}$ formed when dosing with $\mathrm{O}_{2}$ gas. ${ }^{22,23}$ Natural passivation layers formed at atmospheric pressure at near $30 \%$ relative humidity and room temperature are believed to be primarily composed of $\mathrm{Cu}_{2} \mathrm{O}$, with a thin layer of $\mathrm{CuO}$ on top and capped off with a layer of $\mathrm{Cu}(\mathrm{OH})_{2}{ }^{24}$ Analysis of the peak areas yields the composition of each of the surfaces examined, and these are listed in Table 3.

Table 2: XPS Sampling Depths (nm) for Surface Chemical Species and Scans

\begin{tabular}{|c|cccccc|}
\hline & $\theta$ & $\mathbf{C ~ 1 s}$ & $\mathbf{O ~ 1 s}$ & $\mathbf{C u} 3 \mathbf{s}$ & Cu 2p & Cu LMM \\
\hline BE & - & 284.7 & 530.5 & 122.5 & 931.7 & 568.0 \\
KE & - & 1201.9 & 956.1 & 1364.1 & 554.9 & 918.6 \\
$\lambda_{\mathbf{n}}$ & - & 3.6 & 3.2 & 3.8 & 2.4 & 3.1 \\
& & & & & & \\
normal scan* & $46.9^{\circ}$ & 7.3 & 6.5 & 7.8 & 5.0 & 6.4 \\
bulk scan & $18.7^{\circ}$ & 10.1 & 9.0 & 10.8 & 6.9 & 8.8 \\
mid-depth scan & $51.3^{\circ}$ & 67 & 6.0 & 7.1 & 4.5 & 5.8 \\
surface scan & $70.3^{\circ}$ & 3.6 & 3.2 & 3.8 & 2.4 & 3.2 \\
\hline
\end{tabular}

*non-angle resolved. 


\begin{tabular}{|c|c|c|c|}
\hline $01 \mathrm{~s}$ & $\mathrm{Cu} 2 \mathrm{p}$ & $\mathrm{Cu} L \mathrm{LM} M$ & \\
\hline $\begin{array}{l}\mathrm{Cu}(\mathrm{OH})_{2} \\
\mathrm{H}_{2} \mathrm{O} \\
\mathrm{Cu}_{2} \mathrm{O}\end{array}$ & $\begin{array}{l}\mathrm{Cu} \text { or } \\
\mathrm{Cu}_{2} \mathrm{O}\end{array}$ & $\mathrm{Cu}_{2} \mathrm{O}$ & $-2 \mathrm{~nm}$ \\
\hline $\begin{array}{l}\mathrm{Cu}_{2} \mathrm{O} \\
\mathrm{Ou}\left(\mathrm{CH}_{2}\right. \\
\text { or } \mathrm{CH}^{2}\end{array}$ & $\begin{array}{c}\mathrm{Cu} \text { or } \\
\mathrm{Cu}_{2} \mathrm{O} \\
\because\end{array}$ & $\begin{array}{l}\mathrm{O}_{2} \mathrm{O} \\
\mathrm{Cu}^{\prime} \\
\mathrm{OuO}\end{array}$ & $\begin{array}{r}-4 \mathrm{~nm} \\
-6 \mathrm{~nm}\end{array}$ \\
\hline & & & $-8 \mathrm{~nm}$ \\
\hline
\end{tabular}
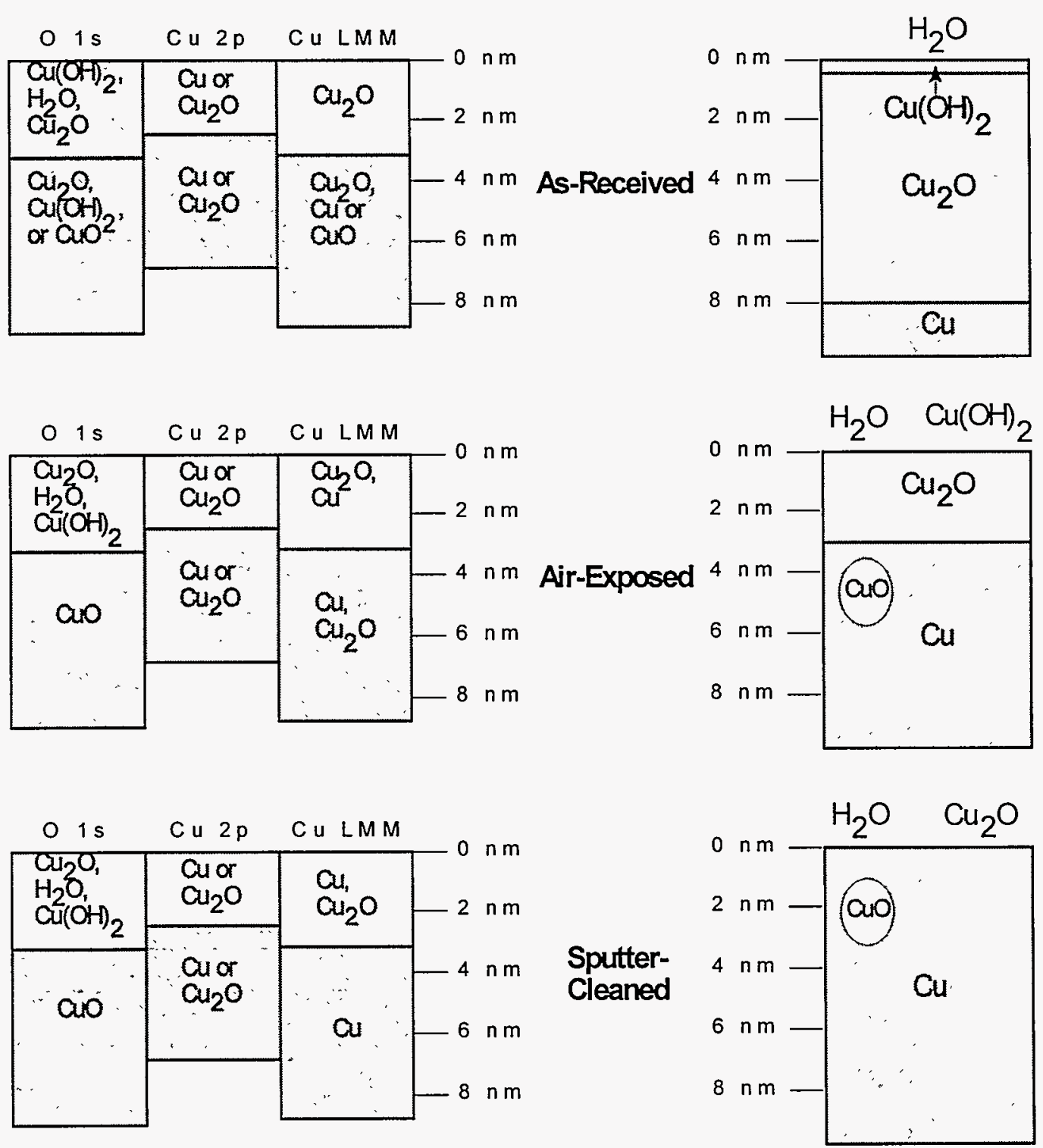

Figure 18: Illustration of the chemical species observed as a function of depth for each of the surface conditions studied. The drawings on the left show the species observed for each XPS region. The species listed on top for each block is the predominant species. Additional species observed are separated by commas while species that are of uncertain assignment are separated by "or". The sampling depths for each peak are shown as the height of the block for the surface and bulk scans. The drawings on the right show the interpretation of this data into the actual surface structures versus depth proposed for each sample condition. 
Table 3: XPS Surface Compositions (Atomic \%)

\begin{tabular}{|c|ccc|ccc|ccc|}
\hline & \multicolumn{3}{|c|}{ Normal Scan } & \multicolumn{3}{c|}{ Bulk Scan } & \multicolumn{3}{c|}{ Surface Scan } \\
Surface & $\mathbf{C}$ & $\mathbf{O}$ & $\mathbf{C u}$ & $\mathbf{C}$ & $\mathbf{O}$ & $\mathbf{C u}$ & $\mathbf{C}$ & $\mathbf{O}$ & $\mathbf{C u}$ \\
\hline As-Received & 59.8 & 29.3 & 10.9 & - & - & - & - & - & - \\
Vacuum-Reduced & 64.7 & 16.8 & 18.5 & 53.1 & 28.8 & 18.1 & 72.3 & 16.1 & 11.6 \\
Heated to $300^{\circ} \mathbf{C}$ & 72.8 & 15.5 & 11.7 & 60.3 & 17.8 & 22.0 & 77.7 & 13.7 & 8.6 \\
Heated to 330 $^{\circ} \mathbf{C}$ & 83.3 & 10.2 & 6.5 & 77.5 & 9.9 & 12.6 & 89.6 & 7.5 & 2.9 \\
Air-Exposed & 15.0 & 27.0 & 58.0 & 7.3 & 18.1 & 74.7 & 23.7 & 29.1 & 47.2 \\
Sputter-Cleaned & 0.0 & 0.0 & 100.0 & 0.0 & 0.0 & 100.0 & 12.1 & 3.4 & 84.5 \\
\hline
\end{tabular}




\subsection{Summary and Conclusions}

A UHV surface analysis system has been specially modified for the in situ study of liquid metal interactions with solid surfaces. This system has been applied to the study of pure tin solder spreading on copper substrate surfaces. A complete description of this system has been given in the text to illustrate its flexibility and utility. This system consists of two separate chambers, one for standard UHV surface analysis and preparation, the other for dynamic liquid solder spreading experiments and higher pressure gas-phase reactions. The sample may be moved between the chambers without interim exposure to contaminating atmospheres and heating stages are available in each chamber. This system allows the in situ study of spreading kinetics on carefully prepared and fully characterized substrate surfaces, in order to determine the role of surface oxidation and contamination on the kinetics of solder spreading. A sophisticated video monitoring system has been set up to provide real-time monitoring of the spreading process from both the top and side of the solder drop. Video recording of the spreading process allows image analysis of the tapes at a later time to obtain detailed spreading rate data. A titanium furnace inert gas purifier allows the experiments to be conducted under 50 torr of extremely pure helium, allowing for good heat conduction to the sample to provide thermal coupling between the solder and the substrate. Melting experiments as a function of helium pressure were used to determine 50 torr as the ideal inert gas pressure to accomplish this goal with a minimum of gas-phase induced contamination problems.

In order to determine the basic spreading dynamics of tin on copper substrate surfaces, initial experiments used a linear temperature ramp to heat the substrate surfaces. The ramp data show that tin will spread readily on all copper substrate surfaces examined, in spite of the fact that no fluxing agents have been used in these studies. However, the temperature must be considerably above the melting temperature of the tin for rapid spreading to occur. Large differences in spreading temperatures, rates and areas of spread were observed as a function of the oxide thickness on the substrate surface. A fundamental difference in spreading behavior is observed on the sputter-cleaned surface, relative to surfaces containing any thickness of oxide, which suggests that the spreading process may be very different on the sputter-cleaned surface. As oxide thickness is decreased, the temperature of the initiation of spreading decreases. On a sputter-cleaned surface, the tin begins spreading as soon as melting occurs, while spreading does not begin on the as-received surface until the temperature is $80^{\circ} \mathrm{C}$ above the melting temperature. In fact, spreading begins on the as-received surface at about the same temperature as that observed where the isothermal spreading dramatically increases its rate. In addition, as oxide thickness is decreased, the rate of spreading increases. There is more than a factor of 10 difference in the spreading rate on the sputter-cleaned surface relative to the as-received surface.

In order to determine the detailed spreading kinetics of tin on the as-received copper substrate surfaces, isothermal spreading experiments were performed. The linear temperature ramp spreading threshold was used to determine the range of temperatures to study in the isothermal experiments. The initial linear rapid spreading data was used to determine the spreading rate as a function of temperature. Slight increases in substrate temperature give rise to large increases in the rate of spreading. Relatively rapid spreading rates are achieved on the as-received copper substrate surfaces at temperatures as low as $30^{\circ} \mathrm{C}$ above the melting temperature of the tin, even in the complete absence of a fluxing agent. Spreading is very rapid at temperatures nearly $100^{\circ} \mathrm{C}$ above the melting 
temperature. These results indicate that solder spreading on the as-received copper surface is a thermally activated process. Analysis of the Arrhenius plot yields an activation energy of $39.4 \pm 3.1$ $\mathrm{kcal} / \mathrm{mole}$ for spreading from 262 to $327^{\circ} \mathrm{C}$. Above $327^{\circ} \mathrm{C}$ there appears to be a change in activation energy or mechanism for the spreading process, presumably due to a change in the surface chemistry of the copper substrates, as noted below.

The surface chemistry of each of the type of copper substrate surfaces used in this study was thoroughly examined by XPS, using angle-resolved analysis in order to determine the depth distribution of observed species. By comparing the species observed for each elemental region and average detection angle, an estimate was made as to the depth distribution of the various chemical species observed on each of the copper substrate surfaces. The as-received copper substrate consists of a thick layer of $\mathrm{Cu}(\mathrm{OH})_{2}$ that is modified very quickly with either vacuum exposure or elevated temperatures in an inert atmosphere. After stabilization by vacuum reduction, the substrate consists of about $8.0 \mathrm{~nm}$ of $\mathrm{Cu}_{2} \mathrm{O}$ on top of metallic $\mathrm{Cu}$, capped off by about a monolayer $(0.3 \mathrm{~nm})$ of $\mathrm{Cu}(\mathrm{OH})_{2}$. The air-exposed copper substrate consists of about $3.0 \mathrm{~nm}$ of $\mathrm{Cu}_{2} \mathrm{O}$ on top of metallic $\mathrm{Cu}$, with small amounts of $\mathrm{Cu}(\mathrm{OH})_{2}$ present in the outer monolayer. The sputter-cleaned copper substrate consists of clean metallic $\mathrm{Cu}$, with small amounts of $\mathrm{Cu}_{2} \mathrm{O}$ present in the outer monolayer. All samples have varying amounts of $\mathrm{H}_{2} \mathrm{O}$ and hydrocarbon species adsorbed in the outermost monolayer, while the air-exposed and sputter-cleaned samples have small amounts of lattice oxygen $(\mathrm{CuO})$ present in the near-surface region of the bulk metallic $\mathrm{Cu}$. These surface structures are completely consistent with those expected for these types of substrate preparation.

The as-received copper substrates varied considerably in surface chemical composition from sample to sample, but the surface chemical composition was made more consistent by heating each sample to $300^{\circ} \mathrm{C}$ prior to adjusting the temperature for the isothermal studies. This preheating converted any remaining $\mathrm{Cu}^{2+}$ species $\left(\mathrm{CuO}\right.$ and $\left.\mathrm{Cu}(\mathrm{OH})_{2}\right)$ present on the surface to $\mathrm{Cu}^{1+}$ species $\left(\mathrm{Cu}_{2} \mathrm{O}\right)$. After the preheating was completed, the remaining $\mathrm{Cu}_{2} \mathrm{O}$ layer was still about $8.0 \mathrm{~nm}$ thick. Upon heating to $330^{\circ} \mathrm{C}$, the amount of oxide present was reduced dramatically, producing a $\mathrm{Cu}_{2} \mathrm{O}$ layer only about $3.0 \mathrm{~nm}$ thick. Although accompanied by a significant increase in carbon present on the surface, this reduction in surface oxide thickness produces a change in the activation energy or a discontinuity in the rate for isothermal spreading and allows rapid spreading to begin in temperature ramp studies. Further work is continuing on identifying the nature of the shift in isothermal rates at $330^{\circ} \mathrm{C}$ and in studying the effect of surface oxide thickness on spreading kinetics.

Metallurgical analysis of samples from the highest and lowest temperature isothermal experiments show no significant change in intermetallic formation or microstructure that can be related to a change in tin/copper interactions throughout the temperature range used for isothermal studies. Both samples show the expected growth layers of $\mathrm{Cu}_{6} \mathrm{Sn}_{5}$ and $\mathrm{Cu}_{3} \mathrm{Sn}$ intermetallic zones, with no apparent inclusions or unwetted areas due to remaining copper oxide in the interfacial zone.

These initial studies clearly show the advantage of this type of approach for examining spreading processes. The combination of classical macroscopic spreading studies, UHV surface analysis techniques and state-of-the art video monitoring produce a unique and beneficial system to study wetting kinetics. In addition, it has been shown that the wetting process can be studied and very significant information can be obtained, even with the very simple model used here of pure tin 
on pure copper in the absence of any fluxing agent. As further studies are completed, any differences due to adding alloy components in the solder composition and addition of a fluxing agent will help determine the respective roles of each of these components in the spreading process. Ultimately, we hope to gain an understanding of how each of the various steps influences the rate and mechanism of solder spreading - solder alloy composition, fluxing action, intermetallic formation and oxide and contaminant presence on the surface. 


\section{References}

1. P. G. de Gennes, Wetting: Statics and Dynamics, in Rev. of Modern Phys., vol. 57, pp. 827$863,1985$.

2. R. T. Beyer and E. M. Ring, The Viscosity of Liquid Metals, in Liquid Metals: Chemistry and Physics, S. Z. Beer, ed., Marcel Dekker, Inc., NY, 1972.

3. L. E. Murr, Interfacial Phenomena in Metals and Alloys, Addison-Wesley Publishing Co., NY, 1975.

4. A. D. Romig, Jr., Y. A. Chang, J. J. Stephens, D. R. Frear, V. Morcotte, and C. Lea, Physical Metallurgy of Solder-Substrate Reactions, in Solder Mechanics: A State of the Art Assessment, D. R. Frear, W. B. Jones, and K. R. Kinsman, eds., The Minerals, Metals, and Materials Society Publication, Warrendale, PA, 1991.

5. G. C. Smith and C. Lea, Wetting and Spreading of Liquid Metals: the Role of Surface Composition, in Surface Interface Anal., vol. 9, pp. 145-150, 1986.

6. A. Savitzky and M. J. E. Golay, Smoothing and Differentiation of Data by Simplified Least Squares Procedures, in Anal. Chem., vol. 36, pp. 1627-1639, 1964.

7. J. Steinier, Y. Termonia and J. Deltour, Comments on Smoothing and Differentiation of Data by Simplified Least Square Procedure, in Anal. Chem., vol. 44, pp. 1906-1909, 1972.

8. H. H. Madden, Comments on the Savitzky-Golay Convolution Method for Least-Squares Fit Smoothing and Differentiation of Digital Data, in Anal. Chem., vol. 50, pp. 1383-1386, 1978.

9. C. D. Wagner, W. M. Riggs, L. E. Davis, J. F. Moulder and G. E. Muilenberg (Editor), Handbook of X-ray Photoelectron Spectroscopy. Perkin-Elmer Corporation, Eden Prairie, Minnesota, 1979.

10. A.-M. Cozabat, How Does a Droplet Spread?, in Contemp. Phys., vol. 28, pp. 347-364, 1987.

11. J. C. Klein, C. P. Li, D. M. Hercules and J. F. Black, Decomposition of Copper Compounds in X-ray Photoelectron Spectrometers, in Appl. Spectrosc., vol. 38, pp. 729-734, 1984.

12. J. P. Tobin, W. Hirschwald and J. Cunningham, XPS and XAES Studies of Transient Enhancement of $\mathrm{Cu}^{1}$ at $\mathrm{CuO}$ Surfaces During Vacuum Outgassing, in Appl. Surface Sci., vol. 16, pp. 441-452, 1983.

13. N. S. McIntyre, S. Sunder, D. W. Shoesmith and F. W. Stanchell, Chemical Information from XPS - Applications to the Analysis of Electrode Surfaces, in J. Vac. Sci. Technol., vol. 18, pp. 714-721, 1981. 
14. L. Pedocchi, A. Billi, E. Marinelli, J. X. Wu and G. Rovida, ESCA Study of the Oxidation of DHP Copper, in Surface Interface Anal., vol. 19, pp. 414-418, 1992.

15. H. D. Speckmann, S. Haupt and H.-H. Strehblow, A Quantitative Surface Analytical Study of Electrochemically-formed Copper Oxides by XPS and X-ray-induced Auger Spectroscopy, in Surface Interface Anal., vol. 11, pp. 148-155, 1988.

16. A. C. Miller and G. W. Simmons, Copper by XPS, in Surface Sci. Spectra, vol. 2, pp. 55-60, 1993.

17. J. C. Klein, A. Proctor, D. M. Hercules and J. F. Black, X-ray Excited Auger Intensity Ratios for Differentiating Copper Compounds, in Anal. Chem., vol. 55, pp. 2055-2059, 1983.

18. P. E. Larson, X-ray Induced Photoelectron and Auger Spectra of $\mathrm{Cu}, \mathrm{CuO}, \mathrm{Cu}_{2} \mathrm{O}$ and $\mathrm{Cu}_{2} \mathrm{~S}$ Thin Films, in J. Electron Spectrosc. Related Phenom., vol. 4, pp. 213-218, 1974.

19. J. Li, G. Vizkelethy, P. Revesz, J. W. Mayer and K. N. Tu, Oxidation and Reduction of Copper Oxide Thin Films, in J. Appl. Phys., vol. 69, pp. 1020-1029, 1991.

20. L. Z. Zhao, S. H. Liu, D. H. Wang and C. H. Pan, XPS Studies of Oxide Films on Transition Metals, in J. Electron Spectrosc. Related Phenom., vol. 52, pp. 571-580, 1990.

21. M. P. Seah and W. A. Dench, Quantitative Electron Spectroscopy of Surfaces: A Standard Data Base for Electron Inelastic Mean Free Paths in Solids, in Surface Interface Anal., vol. 1, pp. 2-11, 1979.

22. P. Stefanov and Ts. Marinova, Adsorption of Oxygen and Formation of an Oxide Phase on a Cu(100) Surface, in Appl. Surface Sci., vol. 31, pp. 445-450, 1988.

23. H. W. Pickering, Initial Stages of Oxidation of $\mathrm{Cu}, \mathrm{Ni}$ and $\mathrm{Cu}-1 \% \mathrm{Fe}$ by Atom-Probe Field Ion Microscopy, in Proceedings of the Symposium on Applications of Surface Analytical Methods to Environmental/Materials Interactions, held in Seattle, Washington, Dec. 16, 1990. Electrochemical Society, Pennington, New Jersey, 1991.

24. T. L. Barr, ESCA Studies of Metals and Alloys: Oxidation, Migration and Dealloying of Cubased Systems, in Surface Interface Anal., vol. 4, pp. 185-193, 1982. 
External Distribution:

1 Dr. J. Lee Parker

AT\&T

4500 Laburnum Avenue

Richmond, VA 23231

1 Dr. Bob Opila

AT\&T

Bell Laboratories

600 Mountain Avenue

Murray Hill, NJ 07974

1 Mr. George Wenger

AT\&T-ERC

P. O. Box 900

Princeton, NJ 08540-0900

1 Dr. Ed Fey

IBM

1701 North Street

Bldg. 257-2

Endicott, NY 13760

25 Mr. Ron Evans

NCMS

3025 Boardwalk

Ann Arbor, MI 48108-1779

1 Ms. Tracy Pattok

NCMS

3025 Boardwalk

Ann Arbor, MI 48108-1779

1 Dr. John R. Manning

NIST

Materials Bldg. A 153

Gaithersburg, MD 20899

1 Alan Burkett

Texas Instruments

2501 S. Highway 121

P. O. Box 4053464

Lewisville, TX 75067
1 Mr. Jim Reed

Texas Instruments

P. O. Box 149149

Austin, TX 78714-9149

1 Mr. Charles DeSantis

United Technologies Corporation

Hamilton Standard Division

One Hamilton Road

Windsor Locks, CT 06096-1010

1 Mr. Jay Kokas

United Technologies Corporation

Hamilton Standard Division

One Hamilton Road

Windsor Locks, CT 060986-1010

3 Prof. M. W. Weiser

Department of Mechanical Engineering University of New Mexico

Albuquerque, NM 87131

1 Prof. J. Adin Mann, Jr.

Department of Chemical Engineering

Case Western Reserve University

Cleveland, OH 44106

1 Prof. John M. White

Chemistry Department

University of Texas

Austin, TX 78712

1 Prof. John T. Yates

2788 Shamrock Street

Allison Park, PA 15101 


\section{Internal Distribution:}

$1 \quad$ MS 0161 M. Moss, 11510

1 MS 0337 A. D. Romig, 1800

1 MS 0339 J. L. Jellison, 1803

1 MS 0340 M. J. Cieslak, 1831

1 MS 0340 M. Essien, 1831

1 MS 0340 C. L. Hernandez, 1831

1 MS 0340 E. A. Holm, 1831

1 MS 0340 F. M. Hosking, 1831

1 MS 0340 D. O. MacCallum, 1831

1 MS 0340 J. A. Rejent, 1831

25 MS 0340 S. J. Sackinger, 1831

1 MS 0340 T. Swiler, 1831

1 MS 0340 P. T. Vianco, 1831

25 MS 0340 F. G. Yost, 1831

1 MS 0340 W. R. Cieslak, 1832

1 MS 0340 D. R. Frear, 1832

1 MS 0340 N. R. Sorensen, 1832

1 MS 0342 C. A. Drewein, 1822

1 MS 0344 R. R. Rye, 1114

1 MS 0344 N. D. Shinn, 1114

1 MS 0367 C. L. Renschler, 1812

5 MS 0367 J. A. Ohlhausen, 1812

25 MS 0367 D. E. Peebles, 1812

1 MS 0368 J. H. Aubert, 1815

1 MS 0368 M. J. Hurst, 1815

5 MS 0368 H. C. Peebles, 1815

1 MS 0609 T. R. Guilinger, 1841

1 MS 0609 J. O. Stevenson, 1841

1 MS 0957 G. L. Cessac, 2411

1 MS 9018 Central Technical Files, 8523-2

5 MS 0899 Technical Library, 7141

1 MS 0619 Technical Publications, 7151

10 MS 1119 Document Procesing, 7613-2

For DOE/OSTI 